\title{
Reversal of Pathologic Lipid Accumulation in NPC1-Deficient Neurons by Drug-Promoted Release of LAMP1-Coated Lamellar Inclusions
}

\author{
V) Valérie Demais, ${ }^{1}$ Amélie Barthélémy, ${ }^{2}$ Martine Perraut, ${ }^{2}$ Nicole Ungerer, ${ }^{2}$ CCéline Keime, ${ }^{3}$ Sophie Reibel, ${ }^{4}$ \\ and Frank W. Pfrieger ${ }^{2}$ \\ 1Plateforme Imagerie In Vitro, CNRS UPS 3156, Neuropôle, 67084 Strasbourg, France, ${ }^{2}$ Institute of Cellular and Integrative Neurosciences, CNRS UPR 3212 , \\ University of Strasbourg, 67084 Strasbourg, France, ${ }^{3}$ Institut de Génétique et de Biologie Moléculaire et Cellulaire, CNRS/INSERM/University of Strasbourg, \\ 67400 Illkirch-Graffenstaden, France, and ${ }^{4}$ Chronobiotron UMS 3415, 67084 Strasbourg, France
}

\begin{abstract}
Aging and pathologic conditions cause intracellular aggregation of macromolecules and the dysfunction and degeneration of neurons, but the mechanisms are largely unknown. Prime examples are lysosomal storage disorders such as Niemann-Pick type C (NPC) disease, where defects in the endosomal-lysosomal protein NPC1 or NPC2 cause intracellular accumulation of unesterified cholesterol and other lipids leading to neurodegeneration and fatal neurovisceral symptoms. Here, we investigated the impact of NPC1 deficiency on rodent neurons using pharmacologic and genetic models of the disease. Improved ultrastructural detection of lipids and correlative light and electron microscopy identified lamellar inclusions as the subcellular site of cholesterol accumulation in neurons with impaired NPC1 activity. Immunogold labeling combined with transmission electron microscopy revealed the presence of CD63 on internal lamellae and of LAMP1 on the membrane surrounding the inclusions, indicating their origins from intraluminal vesicles of late endosomes and of a lysosomal compartment, respectively. Lamellar inclusions contained cell-intrinsic cholesterol and surface-labeled GM1, indicating the incorporation of plasma membrane components. Scanning electron microscopy revealed that the therapeutic drug candidate $\beta$-cyclodextrin induces the subplasmalemmal location of lamellar inclusions and their subsequent release to the extracellular space. In parallel, $\beta$-cyclodextrin mediated the NPC1-independent redistribution of cholesterol within neurons and thereby abolished a deleterious cycle of enhanced cholesterol synthesis and its intracellular accumulation, which was indicated by neuron-specific transcript analysis. Our study provides new mechanistic insight into the pathologic aggregation of macromolecules in neurons and suggests exocytosis as cellular target for its therapeutic reversal.
\end{abstract}

Key words: cholesterol metabolism; electron microscopy; exocytosis; inborn errors metabolism; lysosome; transcript profiling

\section{Significance Statement}

Many neurodegenerative diseases involve pathologic accumulation of molecules within neurons, but the subcellular location and the cellular impact are often unknown and therapeutic approaches lacking. We investigated these questions in the lysosomal storage disorder Niemann-Pick type C (NPC), where a defect in intracellular cholesterol transport causes loss of neurons and fatal neurovisceral symptoms. Here, we identify lamellar inclusions as the subcellular site of lipid accumulation in neurons, we uncover a vicious cycle of cholesterol synthesis and accretion, which may cause gradual neurodegeneration, and we reveal how $\beta$-cyclodextrin, a potential therapeutic drug, reverts these changes. Our study provides new mechanistic insight in NPC disease and uncovers new targets for therapeutic approaches.

\section{Introduction}

Aging and many pathologic conditions induce the formation of aberrant macromolecular complexes in neurons that cause dysfunction and degeneration. Examples are the age-dependent for- mation of lipofuscin (Nowotny et al., 2014) and the pathologic aggregation of macromolecules in Alzheimer's disease (Lim and Yue, 2015) and lysosomal storage disorders (Samie and Xu, 2014; Parenti et al., 2015). In most cases, it is unknown where the 
macromolecular complexes form, how they damage neurons, and whether they can be dissolved. We have addressed these key questions in Niemann-Pick type C (NPC) disease (OMIM \#257220), a rare and ultimately fatal autosomal recessive lysosomal storage disorder with aggravating neurologic symptoms (Vance and Karten, 2014; Vanier, 2015) due to progressive neurodegeneration in specific brain areas (Tanaka et al., 1988; German et al., 2001; Yamada et al., 2001; Luan et al., 2008). The disease is caused by genetic defects in NPC1 or NPC2, which are located in the membrane and lumen of late endosomes, respectively (Loftus et al., 1997; Naureckiene et al., 2000). The dysfunction of NPC1 or NPC2 causes accumulation of unesterified cholesterol in the endosomal-lysosomal system (Sokol et al., 1988; Liscum et al., 1989; Kobayashi et al., 1999), which can be detected by cytochemical staining with the fluorescent polyene filipin (Gimpl, 2010). The presence of filipin-positive "perinuclear vesicles" in patient-derived fibroblasts has served as a key diagnostic indicator of NPC disease (Vanier, 2015).

To study pathologic lipid accumulation and its impact on CNS neurons, we have used retinal ganglion cells (RGCs) as an experimental model. These neurons depend on cholesterol import in vitro (Mauch et al., 2001; Nieweg et al., 2009), they are affected by NPC1 deficiency in humans (Palmer et al., 1985) and mice (Claudepierre et al., 2010), and they can be highly purified, allowing for neuron-specific analyses (Meyer-Franke et al., 1995).

\section{Materials and Methods}

Preparation of RGCs. Experimental procedures involving animals and their care were performed in accordance with European and French regulations on animal experimentation (Directive 63/2010 CEE). Animals of either sex were used. For in vitro experiments, RGCs were purified from 1-week-old Wistar rats (Chronobiotron UMS 3415, Strasbourg, France). For ex vivo experiments, RGCs were purified from 1-week-old $\mathrm{BALB} / \mathrm{c}$ mice homozygous for the recessive NIH allele of $\mathrm{Npcl}$ or from wild-type littermates (BALB/cNctr-Npc1 ${ }^{\mathrm{m} 1 \mathrm{~N}} / \mathrm{J}$; Stock 003092; The Jackson Laboratory; Chronobiotron UMS 3415). Mice were genotyped as described previously (Buard and Pfrieger, 2014). RGCs were purified from rats (Meyer-Franke et al., 1995) and mice (Steinmetz et al., 2006) as described with some modifications. Briefly, animals were anesthetized and killed by decapitation. Retinae were dissected and subjected to mechanic and enzymatic dissociation (Neural Tissue Dissociation Kit, Postnatal Neurons, Miltenyi Biotec). RGCs were purified using a subtraction (for rats, primary: rabbit anti-rat macrophage, Axell/WAKChemie, catalog \#AI-A51240; secondary: goat anti-rabbit IgG, Jackson ImmunoResearch, catalog \#111-005-003; for mice, the primary antibody was omitted) and a selection step (for rats, primary: mouse anti-rat Thy1.1/CD90 clone T11D7e; secondary: goat anti-mouse IgM, Jackson ImmunoResearch, catalog \#115-005-003; for mice, primary: mouse antimouse CD90 clone F7D5, Bio-Rad, catalog \#MCA02R; secondary: goat anti-mouse IgM). RGCs were plated as indicated. For ex vivo experiments, mouse RGCs were used directly after purification or subjected to short-term culture for a maximum of $30 \mathrm{~h}$. For in vitro experiments, rat RGCs were cultured in serum-free medium (Neurobasal, Invitrogen) supplemented with MACS Neurobrew-21 (Miltenyi Biotec), brainderived neurotrophic factor ( $25 \mathrm{ng} / \mathrm{ml}$; PeproTech), ciliary neurotrophic factor (10 ng/ml; PeproTech), forskolin (10 $\mu \mathrm{M}$; Sigma), glutamine (2 $\mathrm{mm}$; Invitrogen), $\mathrm{N}$-acetylcysteine $(60 \mu \mathrm{g} / \mathrm{ml}$; Sigma), penicillin $(100$

The authors declare no competing financial interests.

Correspondence should be addressed to Frank W. Pfrieger, Institute of Cellular and Integrative Neurosciences, CNRS UPR 3212, University of Strasbourg, 5 Rue Blaise Pascal, 67084 Strasbourg, France. E-mail: fw-pfrieger@gmx.de.

DOI:10.1523/JNEUROSCI.0900-16.2016

Copyright $\odot 2016$ the authors $\quad 0270-6474 / 16 / 368013-14 \$ 15.00 / 0$ units/ml; Invitrogen), sodium pyruvate (1 mm; Invitrogen), and streptomycin $(100 \mu \mathrm{g} / \mathrm{ml}$; Invitrogen $)$. Unless indicated otherwise, experiments were performed on RGCs treated with glia-conditioned medium (GCM) starting after $1 \mathrm{~d}$ in culture. GCM was prepared as described previously (Nieweg et al., 2009). Briefly, mechanically dissociated cortices from postnatal day 1 (P1)-P3 Wistar rats were cultured in poly-D-lysine (PDL)-coated (10 $\mu \mathrm{g} / \mathrm{ml}$; Sigma, catalog \#P7886) tissue culture plates (diameter, $10 \mathrm{~cm}$; BD Falcon, catalog \#353003) in DMEM (catalog \#21969), heat-inactivated fetal calf serum (10\%), penicillin (100 units/ $\mathrm{ml})$, streptomycin $(100 \mu \mathrm{g} / \mathrm{ml})$, and glutamine (2 mM; all from Invitrogen). After 2 weeks, culture plates were washed with PBS, and glial cells were cultured in Neurobasal medium supplemented with glutamine (2 $\mathrm{mm})$, penicillin (100 units $/ \mathrm{ml})$, sodium pyruvate $(1 \mathrm{~mm})$, streptomycin $(100 \mu \mathrm{g} / \mathrm{ml})$, and NS21. Two times a week, fresh medium was added, and GCM was harvested after 2 weeks. GCM was spun down $(5$ min at $3000 \times$ $g$ ) to remove cellular debris and used immediately or stored at $-20^{\circ} \mathrm{C}$. For GCM treatment, two-thirds of the RGC medium was replaced by GCM. As a control, corresponding amounts of medium from RGC cultures were replaced by fresh culture medium. Unless indicated otherwise, rat RGCs were treated with 3- $\beta$-[2-(diethylamine)ethoxy] androst-5-en17-one [U18666A (U18); Interchim] after $2 \mathrm{~d}$ in culture at a concentration of $0.5 \mu \mathrm{g} / \mathrm{ml}$ for $48 \mathrm{~h}$. Some cultures were treated for $24-30 \mathrm{~h}$ with 2-hydroxypropyl- $\beta$-cyclodextrin (HbC) [Sigma catalog \#H5784; molecular weight (MW), $\sim 1400 ; 50 \mu \mathrm{M} \sim 70 \mu \mathrm{g} / \mathrm{ml} \sim 0.007 \%(\mathrm{w} / \mathrm{v})]$, with sulfobutylether- $\beta$-cyclodextrin (SbC; Captisol, Ligand Pharmaceuticals; MW, 2163) or with 2-hydroxypropyl- $\alpha$-cyclodextrin (HaC; Sigma/Aldrich, catalog \#390690; MW, 1180).

Viability test and cytochemical and immunocytochemical staining. RGCs were plated on PDL-coated, 96-well microplates (7000 cells per well; black/clear imaging plate; BD Falcon, catalog \#353219). Neuronal survival was measured using the Live/Dead viability assay according to the manufacturer's instructions (Invitrogen). For cytochemical detection of cholesterol, RGCs were fixed by paraformaldehyde [PFA; $4 \%$ in PBS for $15 \mathrm{~min}$ at room temperature (RT)] and subjected to staining with filipin $(40 \mu \mathrm{g} / \mathrm{ml}$ in PBS for $2 \mathrm{~h}$ at RT; from 250 -fold ethanolic stock solution; Sigma, catalog \#F9765). To label surface-resident ganglioside GM1, RGCs were cultured for indicated periods of time in the presence of biotinylated cholera toxin B (CTB) subunit (10 ng/ml; Sigma, catalog \#C9972), fixed with PFA (4\% for 15 min at RT) and reacted with Alexa 488-coupled streptavidin (1:50; Nanoprobes). For immunocytochemistry, RGCs were fixed with PFA ( $4 \%$ for $15 \mathrm{~min}$ at RT), permeabilized with sodium borohydride $\left[0.05 \% \mathrm{NaBH}_{4}(\mathrm{w} / \mathrm{v})\right.$ in $\mathrm{PBS}$ for $\left.15 \mathrm{~min}\right]$, and blocked with bovine serum albumin (BSA; 3\% in PBS for $15 \mathrm{~min}$ ). Staining with primary (diluted in 3\% BSA/PBS) and secondary antibodies (in PBS; Alexa 594 goat anti-rabbit at 1:1000 and Alexa 488 goat anti-mouse at 1:1000; Invitrogen; from a 50\% glycerol/PBS stock) was performed overnight at $4^{\circ} \mathrm{C}$ and for $1 \mathrm{~h}$ at RT, respectively. Nuclei were stained with 4',6-diamidino-2-phenylindole dihydrochloride (DAPI; $100 \mathrm{ng} / \mathrm{ml}$ for 5 min at RT; Sigma, catalog \#D9542). Primary antibodies against the following proteins were used: ARHGAP9 (1:250; rabbit polyclonal; Santa Cruz Biotechnology, catalog \#Sc-135084), CD63 (for rats, 1:2000, mouse monoclonal, Abcam, catalog \#Ab108950; for mice, 1:1000 goat polyclonal, Santa Cruz Biotechnology, catalog \#Sc-31214), hexosaminidase A (1:500; rabbit polyclonal; Novus Biologicals, catalog \#NBP1-74127); HMGCR (1:2000; rabbit polyclonal; US Biological, catalog \#211303), and LAMP1 (1:2000; rabbit polyclonal; Abcam, catalog \#Ab24170). Fluorescence and phase-contrast images of cells were acquired on an inverted microscope (Axiovert 135TV; Zeiss) equipped with a metal halide lamp (10\%; Lumen 200, Prior Scientific), appropriate excitation/emission filters (Filipin, XF02-2; Alexa 488, XF100-1; Alexa 594, XF102-2; Omega Optical) and objectives ( $10 \times$ or $40 \times$ oil, 1.3 numerical aperture; Zeiss), and an air-cooled monochrome CCD camera (Sensicam, PCO Computer Optics) controlled by custom-written LabVIEW routines (National Instruments). Fluorescence micrographs were analyzed using ImageJ (version 1.43u) and custom-written LabVIEW routines to detect somata (viability assay) and labeled puncta (cytochemical and immunocytochemical staining). For soma detection, fluorescence images (10X objective) were segmented by label-specific intensity thresholds [mean + $\mathrm{SD} \times 2.5$ (calcein) or 4.0 (ethidium)]. To count the number of live 
(calcein-stained) and dead (ethidium-stained) cells, binary images were subjected to particle analysis using empirically determined ranges of radius lengths (calcein, 5-30; ethidium, 2-10 pixels). To detect fluorescent puncta, fluorescence images $(40 \times$ oil) were processed by a Mexican hat filter to enhance puncta-like features using an empirically derived $5 \times 5$ kernel $(0,-2,-2,-2,0 / 0,-2,3,-2,0 /-2,3,12,3,-2 / 0,-2,3,-2$, $0 / 0,-2,-2,-2,0)$. Filtered images were segmented (mean fluorescence intensity plus constant) and subjected to particle detection (minimum area, 3 pixels) within manually outlined somata, which calculated the numbers and coordinates of detected puncta per soma. Colocalization of markers at detected puncta was determined based on correlation of fluorescence intensities $(r>0.5)$ across enlarged particle areas (1.5-fold radius length). Fluorescence intensities of detected puncta were calculated as analog-to-digital conversion units ( 8 bit) integrated over the area ( 3 pixel minimum) and represented by the third quartile per cell.

Hexosaminidase activity. Enzyme activity was measured using a fluorogenic substrate-based assay (Wendeler and Sandhoff, 2009). Briefly, lysate or medium from RGCs $(20 \mu \mathrm{l})$ growing in 96-well plates was incubated at $37^{\circ} \mathrm{C}$ for $3 \mathrm{~h}$ with reaction mix $(40 \mu \mathrm{l})$ containing sodium citrate (10 mM; $\mathrm{pH} 4.2$ ) and 4-methylumbelliferyl-2-acetamido-2deoxy-b-D-glucopyranoside ( $2 \mathrm{~mm}$; Sigma). The reaction was stopped by adding $200 \mu \mathrm{l}$ of $0.2 \mathrm{M}$ glycine $/ 0.2 \mathrm{M} \mathrm{Na}_{2} \mathrm{CO}_{3}$. The fluorescent product 4-methylumbelliferone was measured in triplicate on a microplate reader (Mithras, Berthold Technologies) using suitable excitation $(365 \mathrm{~nm}$ ) and emission filters $(440 \mathrm{~nm})$. Calibration curves were acquired using defined amounts of the fluorescent product in $0.2 \mathrm{M}$ glycine $/ 0.2 \mathrm{M} \mathrm{Na}_{2} \mathrm{CO}_{3}$. Note that these experiments were performed in the absence of GCM due to the high basal hexosaminidase activity in glial culture medium.

Transmission electron microscopy. RGCs plated on PDL-coated coverslips (17,000 per $12 \mathrm{~mm}$ diameter; Assistent No. 1001) were fixed with glutaraldehyde ( $2.5 \%$ in $0.1 \mathrm{M}$ cacodylate buffer at $\mathrm{pH} 7.4$ for $1 \mathrm{~h}$ at RT; Electron Microscopy Services-EMS) and rinsed with cacodylate buffer. In some experiments, cholesterol was stained by filipin $(50 \mu \mathrm{g} / \mathrm{ml}$ for 30 min, from a 100 -fold dimethylformamide stock solution). Cells were postfixed for $1 \mathrm{~h}$ with osmium tetroxide $\left[\mathrm{OsO}_{4} ; 1 \%(\mathrm{w} / \mathrm{v})\right]$ in cacodylate buffer for the conventional protocol or with $\mathrm{OsO}_{4}[2 \%(\mathrm{w} / \mathrm{v})]$ in $0.1 \mathrm{M}$ imidazole buffer for the lipid-preserving protocol before dehydration, embedding, and ultramicrotomy. To detect GM1, RGCs were plated on PDL-coated coverslips, cultured, and incubated with biotinylated CTB (10 ng/ml; Sigma, catalog \#C9972). After indicated times, cells were fixed with PFA (4\%) and glutaraldehyde (0.5\% in PBS at pH 7.4 for $30 \mathrm{~min})$. To inactivate residual aldehyde groups present after aldehyde fixation and to permeabilize cells, samples were incubated with sodium borohydride $\left[0.05 \% \mathrm{NaBH}_{4}(\mathrm{w} / \mathrm{v})\right.$ in PBS for $\left.15 \mathrm{~min}\right]$ and blocked in BSA ( $2 \%$ in PBS, three times for $10 \mathrm{~min}$ each). Cells were incubated with streptavidine-gold particles ( $5 \mathrm{~nm}$; 1:100 in PBS with 0.1\% BSA; Aurion). After several rinses in Sorensen's phosphate buffer (SPB; 0.1 M, pH 7.4), cells were postfixed in glutaraldehyde $(2.5 \%$ in SPB) and washed with $\mathrm{SPB}$ and with distilled water. Cells were postfixed in $\mathrm{OsO}_{4}(0.5 \%$ in aqua bidestillata for $15 \mathrm{~min}$ ).

For immunogold labeling, RGCs plated on PDL-coated glass coverslips were fixed with PFA (4\%) and glutaraldehyde $(0.1 \%$ in PBS at $\mathrm{pH}$ 7.4 for $20 \mathrm{~min}$ ), incubated with sodium borohydride $\left[0.05 \% \mathrm{NaBH}_{4}\right.$ $(\mathrm{w} / \mathrm{v})$ in PBS for $15 \mathrm{~min}$ ], and blocked in BSA (2\% in PBS, three times for $10 \mathrm{~min}$ each). Cells were incubated overnight at $4^{\circ} \mathrm{C}$ with antibodies against LAMP1 (1:100) and CD63 (1:100; all in PBS with 0.1\% BSA). After washing in PBS (2\% BSA), cells were incubated with ultrasmall nanogold $\mathrm{F}\left(\mathrm{ab}^{\prime}\right)$ fragments of goat anti-rabbit or goat anti-mouse immunoglobulin G (1:100 in PBS with 0.1\% BSA; Aurion). After several rinses in SPB, cells were postfixed in glutaraldehyde ( $2.5 \%$ in SPB) and washed with SPB and with distilled water. Gold particles were then silver enhanced using the R-Gent SE-EM kit (Aurion). Immunogold-labeled cells were postfixed in $\mathrm{OsO}_{4}(0.5 \%$ in aqua bidestillata for $15 \mathrm{~min})$. Finally, cells were dehydrated in graded ethanol series and embedded in Embed 812 (EMS). The ultrathin sections were cut with an ultramicrotome (Leica), stained with uranyl acetate $[1 \%(\mathrm{w} / \mathrm{v})$ in $50 \%$ ethanol], and examined with a Hitachi H7500 transmission electron microscope equipped with an Advanced Microscopy Techniques/Hamamatsu digital camera. For quantitative analyses of the endosomal-lysosomal system, the different compartments were identified by well-established ultrastructural criteria (Miller and Palade, 1964; Klumperman and Raposo, 2014). Briefly, endosomes are variably shaped with an electrontranslucent interior, no or few internal vesicles, and clathrin-coated membrane domains. Multivesicular bodies are spherical structures with a fuzzy internal coat and abundant intraluminal vesicles. Primary lysosomes have a homogenously electron-dense vacuolar matrix. Secondary lysosomes show a more dense vacuolar matrix with more or less degraded material. Residual bodies, also called tertiary lysosomes, show degraded material and a compact electron-dense core. Lamellar inclusions are spherical compartments containing few internal membranes, and multilamellar inclusions are densely filled with concentric membrane sheets. For each experimental condition, electron micrographs from at least 40 cells were analyzed using ImageJ.

Correlative light and electron microscopy. RGCs cultured on PDLcoated, gridded, thin-bottom tissue culture plates (30,000 cells; $\mu$ Dish 35 $\mathrm{mm}$, Grid-500; Ibidi) were fixed with glutaraldehyde (2.5\% in PBS at $\mathrm{pH}$ 7.4, for $1 \mathrm{~h}$ at RT), rinsed with PBS, treated with glycine (0.1 $\mathrm{m}$ in PBS; $\mathrm{pH}$ 7.4; for $1 \mathrm{~h}$ at RT) to reduce aldehyde-based fluorescence, and subjected to filipin staining ( $50 \mu \mathrm{g} / \mathrm{ml}$ in PBS for $2 \mathrm{~h}$ at RT, from 100 -fold dimethylformamide stock solution). RGCs were imaged by phase-contrast and fluorescence microscopy, and the grid coordinates were recorded. Samples were then processed for transmission electron microscopy (TEM), and ultrathin sections were cut from areas covering the recorded grid coordinates. Selected filipin-labeled cells from fluorescence micrographs were localized and photographed on serial ultrathin sections at different magnifications. To define the ultrastructural correlate of filipin-positive puncta, masks derived from filipin fluorescence were aligned to electron micrographs from ultrathin sections.

Scanning electron microscopy. To detect cholesterol-rich inclusions, cells on PDL-coated 96-well microplates were fixed with glutaraldehyde ( $2.5 \%$ in $0.1 \mathrm{M}$ cacodylate buffer at $\mathrm{pH} 7.4$; for $1 \mathrm{~h}$ at $\mathrm{RT}$ ) and rinsed with cacodylate buffer. Cholesterol was labeled by filipin $(50 \mu \mathrm{g} / \mathrm{ml}$ for 30 min, from 100-fold dimethylformamide stock solution) and cells were postfixed with $\mathrm{OsO}_{4}[1 \%(\mathrm{w} / \mathrm{v})$ in cacodylate buffer for $1 \mathrm{~h}]$. For combined immunogold labeling and secondary electron and backscattered electron (BSE) imaging, RGCs were fixed with PFA (4\%) and glutaraldehyde $(0.1 \%$ in PBS at pH 7.4 for 20 min). Samples were blocked in BSA ( $2 \%$ in PBS, three times for 10 min each) and incubated overnight at $4^{\circ} \mathrm{C}$ with antibodies against LAMP1 (1:200) and CD63 (rat-specific, 1:200; mouse-specific, 1:50; all in PBS with 0.1\% BSA). After washing in PBS ( $2 \%$ BSA), samples were incubated with gold $F\left(a^{\prime}\right)$ fragments of goat anti-rabbit or goat anti-mouse immunoglobulin G (1:100 in PBS with $0.1 \%$ BSA; Aurion). After several rinses in SPB, cells were postfixed in glutaraldehyde (2.5\% in SPB) before washing with SPB and with distilled water and again postfixed in $\mathrm{OsO}_{4}(0.5 \%$ in water for $15 \mathrm{~min})$.

To visualize the cytoplasmic face of the plasma membrane, cells were prepared as described previously with modifications (Boyles and Bainton, 1979). Briefly, RGCs plated on glass coverslips were covered by a second coverslip and sequeezed to ensure adhesion of the plasma membranes to the glass surface. Coverslips were then ripped apart to fracture cells horizontally and to expose the cytoplasmic side of the plasma membrane. Top and bottom halves of cells attached to each respective coverslip were fixed with PFA (4\%) and glutaraldehyde (0.1\% in PBS at pH 7.4 for $20 \mathrm{~min}$ ). Samples were blocked in BSA ( $2 \%$ in PBS, three times for 10 min each) and incubated overnight at $4^{\circ} \mathrm{C}$ with antibodies against $\beta$-actin (1:200; rabbit polyclonal $\beta$-actin; Abcam, catalog \#ab8227), class III $\beta$-tubulin (TUJ1; 1:200; mouse monoclonal; Covance, catalog \#MMS-435P) and VAMP8 (1:500; rabbit polyclconal; Synaptic Systems, catalog \#104 302; all in PBS with 0.1\% BSA). After washing in PBS (2\% $\mathrm{BSA})$, samples were incubated with gold $\mathrm{F}\left(\mathrm{ab}^{\prime}\right)$ fragments of goat antirabbit or goat anti-mouse immunoglobulin G (1:100 in PBS with $0.1 \%$ BSA; Aurion).

To detect secreted, cholesterol-rich inclusions in neuron-conditioned culture medium, medium was removed from cells, fixed with $2.5 \%$ glutaraldehyde, and added to glass coverslips for sedimentation $(1 \mathrm{~h})$. To detect CD63 and GM1 in secreted inclusions, living RGCs were incubated for $48 \mathrm{~h}$ with biotinylated CTB as described. Medium was fixed with $4 \%$ PFA and $0.1 \%$ glutaraldehyde for $15 \mathrm{~min}$, spun down at 13.4 
A
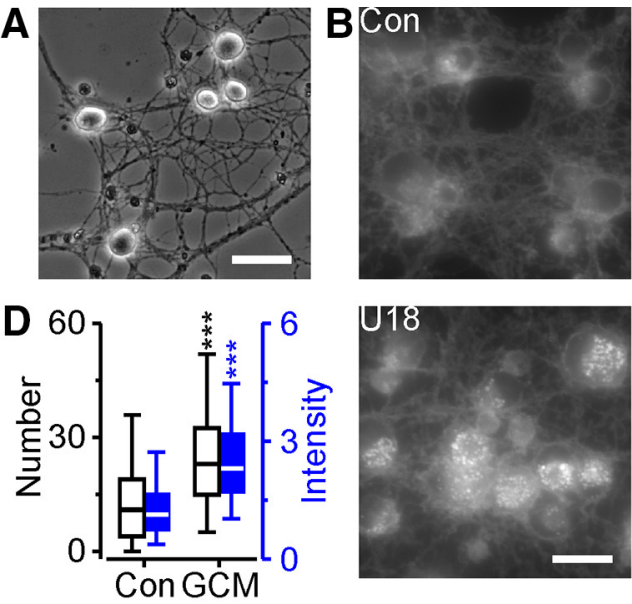

E

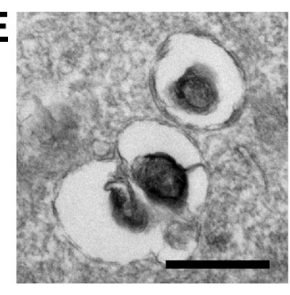

$\mathbf{F}$
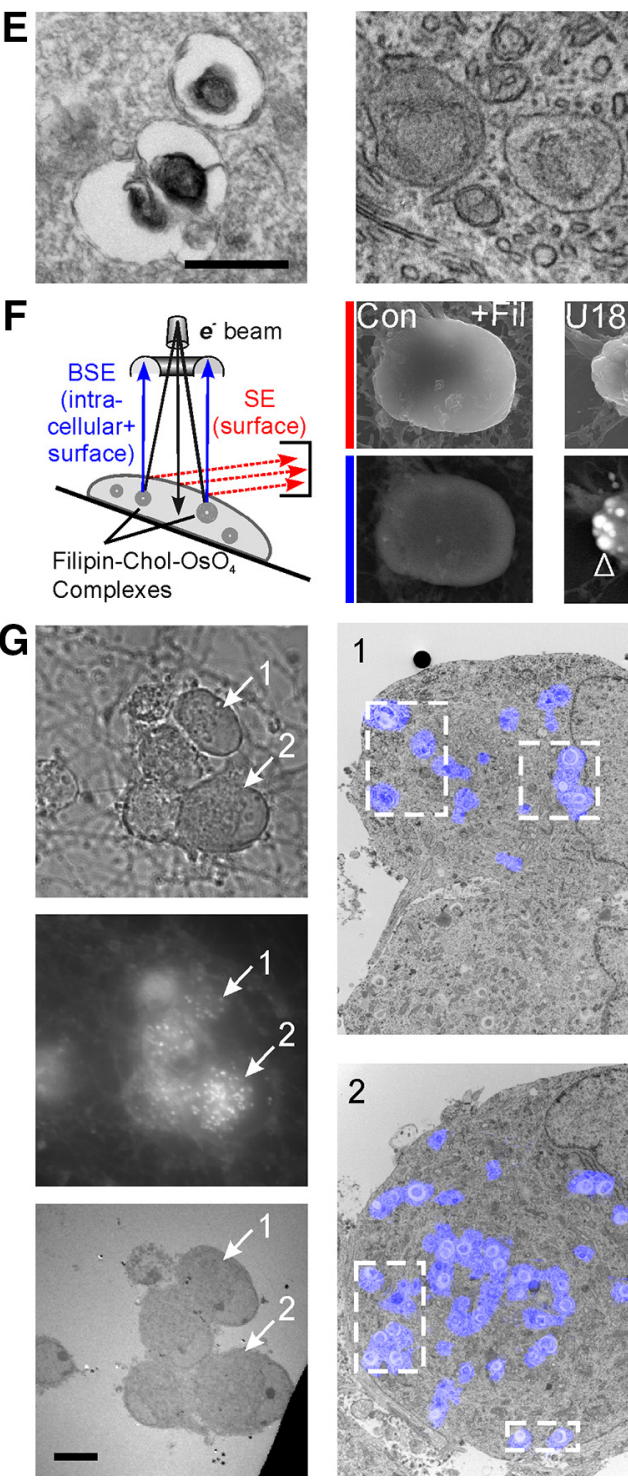
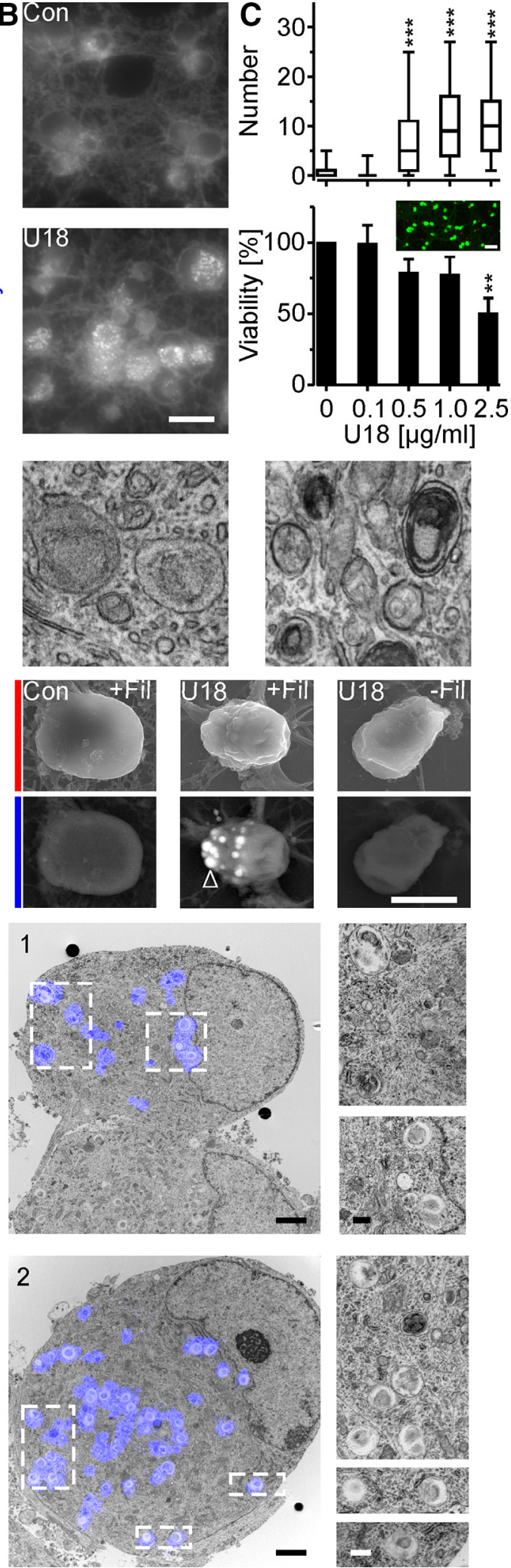

Figure 1. Intracellular localization of U18-induced cholesterol accumulation. $\boldsymbol{A}$, Phase-contrast micrograph showing somata and neurites of RGCs purified by immunopanning from 1-week-old rats and cultured for 4 d under serum- and glia-free conditions $\boldsymbol{B}$, Fluorescence micrographs of RGCs treated without [control (Con)] or with U18 (2.5 $\mu \mathrm{g} / \mathrm{ml}$ for $48 \mathrm{~h})$ and stained with filipin. $\boldsymbol{C}$, Numbers of filipin-positive puncta in somata of RGCs (top; for 0, 0.1,0.5, 1.0, and $2.5 \mu \mathrm{g} / \mathrm{ml}, n=638,557,594,451$, and 678 cells, respectively; 2-3 preparations) and percentage of surviving RGCs (bottom) treated with U18 at indicated concentrations for $48 \mathrm{~h}$. Viability values were normalized to untreated control cultures (3-4 preparations). Inset, False-color fluorescence micrograph showing living (green) and dead (red) RGCs from an untreated control culture. D, Numbers (left axis, white boxes; Con, $n=311$ cells; GCM, $n=328$ cells) and intensities of filipin-positive puncta (right axis, blue boxes; Con, $n=284$ cells; GCM, $n=325$ cells; rpm for $60 \mathrm{~min}$, resuspended in sodium borohydride $(0.05 \%$ in PBS for $15 \mathrm{~min})$, and blocked in BSA (2\% in PBS for 30 min). Pellets were incubated overnight at $4^{\circ} \mathrm{C}$ with an antibody against CD63 (rat-specific, 1:200; in PBS with $0.1 \%$ BSA). After washing in BSA ( $2 \%$ in BSA), pellets were incubated with ultrasmall nanogold $\mathrm{F}\left(\mathrm{ab}^{\prime}\right)$ fragments of goat anti-biotin immunoglobulin $\mathrm{G}$ (1:50 in PBS with $0.1 \%$ $\mathrm{BSA}$; Aurion) overnight at $4^{\circ} \mathrm{C}$. After rinses in SPB and distilled water, gold particles were silver-enhanced for $90 \mathrm{~min}$ using the R-Gent SE-EM kit (Aurion). Pellets were then rinsed in distilled water and SPB and incubated with ultrasmall nanogold $\mathrm{F}\left(\mathrm{ab}^{\prime}\right)$ fragments of goat anti-mouse immunoglobulin G (1:50 in PBS with $0.1 \% \mathrm{BSA}$; Aurion) overnight at $4^{\circ} \mathrm{C}$. Pellets were postfixed in glutaraldehyde $(2.5 \%$ in SPB) and washed with SPB and distilled water. Gold particles were silver-enhanced for $60 \mathrm{~min}$ using the R-Gent SE-EM kit (Aurion).

All samples were dehydrated in graded ethanol series, desiccated in hexamethyldisilazane, and air dried. Samples were carbon coated and examined by scanning electron microscopy at $15 \mathrm{kV}$ (Hitachi S800). Secondary electron and BSE images were collected simultaneously by corresponding detectors. To analyze the surface distribution of LAMP 1 , the $x-y$ coordinates of the gold particles were determined using an ImageJ plug-in (Zhang et al., 2006). Ripley's $k$ function was calculated using the coordinates and then standardized to the $99 \%$ confidence interval of a random pattern (Zhang et al., 2006).

Analysis of gene expression by RNA sequencing. Neuronal RNA was harvested immediately after immunopanning from RGCs still attached to the selection plate using a standard kit according to the manufacturer's instructions (RNeasy Plus Micro Kit, Qiagen, catalog \#74034). After isolation of total RNA from four wild-type and four NPC1-deficient mice (samples; biological replicates), libraries of template molecules suitable for high throughput DNA sequencing were created using the TruSeq RNA Sample Preparation v2 kit (Illumina;

values divided by 1000) in somata of RG(s treated with U18 in the presence or absence of GCM (3 preparations; Mann-Whitney $U$ test). ${ }^{* *} p<0.01$; ${ }^{* * *} p<0.001$. E, Transmission electron micrographs of RGCs treated with U18 and fixed with glutaraldehyde (left) plus imidazole (middle) and plus filipin (right). $\boldsymbol{F}$, Diagram and scanning electron micrographs of RGC somata using secondary electron detection (red, top) to visualize the cell surface and BSE detection (blue, bottom) to detect intracellular filipin-osmiumstained structures (arrowhead) after treatment with U18 and with or without filipin staining as indicated. G, CLEM revealing lamellar inclusions as ultrastructural correlate of filipin-positive puncta in U18-treated RGCs. Left, Phase-contrast (top), fluorescence (middle), and transmission electron micrographs (bottom) of the same group of cells. Numbered arrows point to two RGCs selected for CLEM and shown in the middle panel. Middle, Highermagnification micrographs of selected RGCs with false-color overlays of filipin fluorescence. Right, Magnified areas outlined in the middle panel. Scale bars: $\boldsymbol{A}, 40 \mu \mathrm{m} ; \boldsymbol{B}, 20 \mu \mathrm{m} ; \boldsymbol{C}, 50 \mu \mathrm{m} ; \boldsymbol{E}, \boldsymbol{G}$, right, $500 \mathrm{~nm} ; \boldsymbol{F}, 6 \mu \mathrm{m} ; \boldsymbol{G}$, left, $10 \mu \mathrm{m}$; middle, $2 \mu \mathrm{m}$. 

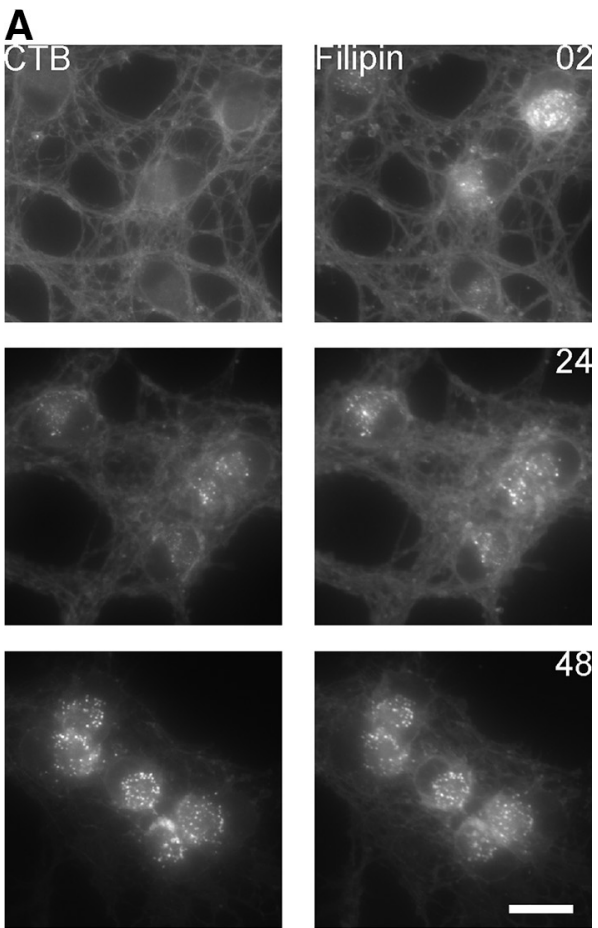

B

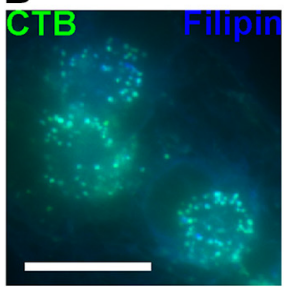

D
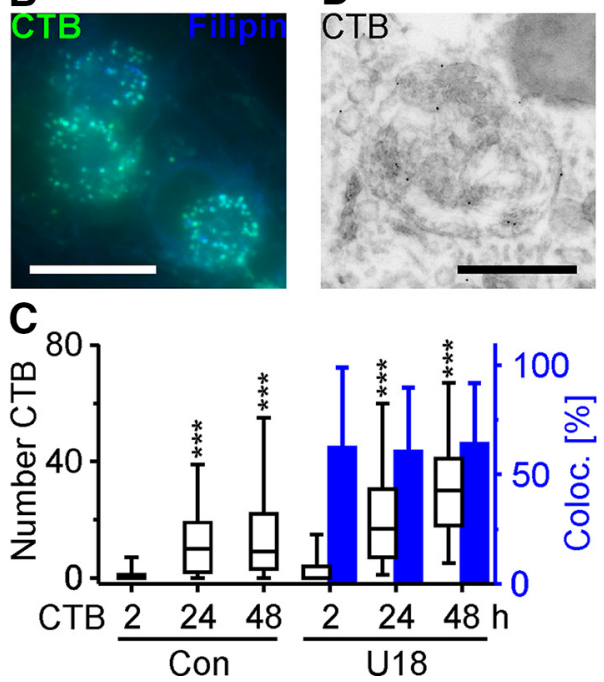

Figure 2. Accumulation of surface-labeled GM1 in cholesterol-rich lamellar inclusions. $A$, Fluorescence micrographs of RGCs treated with U18 and cultured for indicated durations (in hours) in the presence of biotinylated (TB before fixation and filipin staining. $B$, False-color fluorescence micrograph of U18- and CTB-treated RGCS, magnified from $A$, showing overlap of filipin and CTB. C, Number of CTB-positive puncta per soma [left axis, white boxes, СТB $2 \mathrm{~h}$, control (Con), $n=227$ cells; U18, $n=183$ cells; $24 \mathrm{~h}$, Con, $n=135$ cells; U18, $n=208$ cells; $48 \mathrm{~h}$, Con, $n=339$ cells; U18, $n=271$ cells] and mean percentage of CTB-positive puncta colocalizing with filipin (right axis, blue boxes; $2 \mathrm{~h}, n=86 ; 24 \mathrm{~h}, n=198 ; 48 \mathrm{~h}, n=270$ ) at indicated treatments (3 preparations). D, Representative electron micrograph showing CTB gold-labeled GM1 inside a lamellar inclusion of an RGC cultured in the presence of U18 and CTB. ${ }^{* * *} p<0.001$. Scale bars: $A, B, 20 \mu \mathrm{m} ; \boldsymbol{D}, 500 \mathrm{~nm}$.

Plateforme Biopuce et Séquencage, Institut de Génétique et de Biologie Moléculaire et Cellulaire, Illkirch, France). Briefly, mRNA was purified from 120-150 ng of total RNA using poly-T oligo-attached magnetic beads and fragmented using divalent cations at $94^{\circ} \mathrm{C}$ for $8 \mathrm{~min}$. The cleaved mRNA fragments were reverse transcribed to cDNA using random primers, and the second strand of the CDNA was synthesized using DNA polymerase I and RNase $\mathrm{H}$. The double-stranded cDNA fragments were blunted using T4 DNA polymerase, Klenow DNA polymerase, and
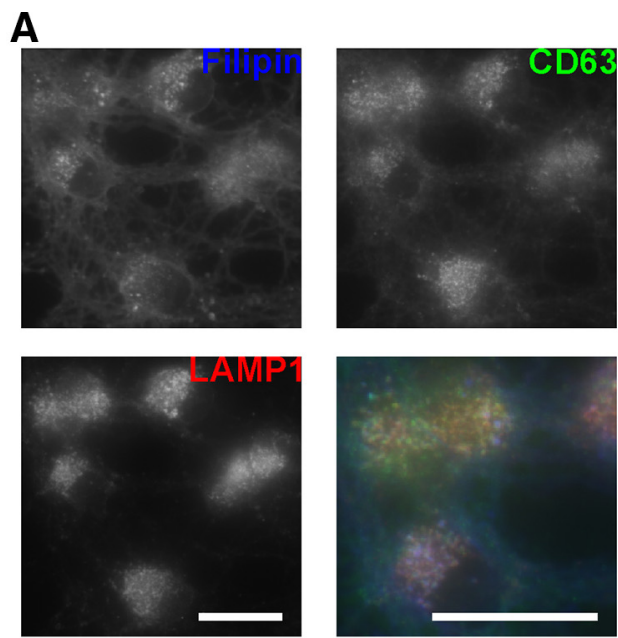

B
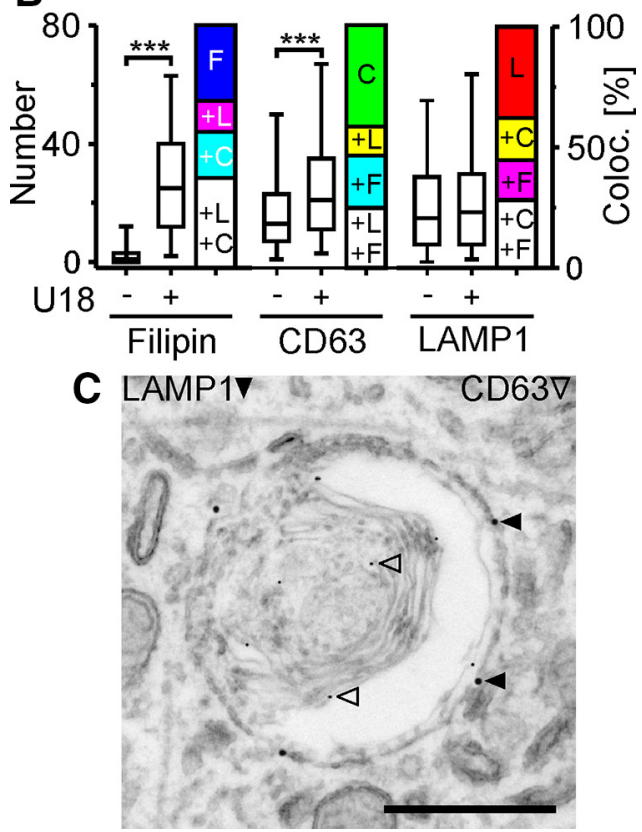

Figure 3. Origin of lamellar inclusions. $A$, Fluorescence micrographs of RGCs treated with U18 and stained as indicated. The false-color micrograph shows colocalization of filipin-positive puncta with endosomal-lysosomal markers in U18-treated cells. B, Left axis, Number of filipin-, LAMP1-, and CD63-positive puncta that were detected in RGCs treated as indicated. Right axis, Percentage of puncta that showed no colocalization with the other markers (top box colored as in $A$; F, filipin, blue; C, CD63, green; L, LAMP1, red), colocalization with only one marker (two middle boxes with color of respective overlap), and colocalization with both markers (bottom box in white indicating overlap of blue, red, and green) in RGCs treated with U18 (control, $n=$ 263; U18, $n=223$ cells; 3 preparations; Mann-Whitney U test). C, Representative electron micrograph of an immunogold-labeled RGC showing LAMP1 (large; filled arrowheads) and CD63 (small; empty arrowheads) on the surrounding membrane and on the lamellae of an U18-induced inclusion, respectively. ${ }^{* * *} p<0.001$. Scale bars: $\boldsymbol{A}, 20 \mu \mathrm{m} ; \boldsymbol{C}, 500 \mathrm{~nm}$.

T4 polynucleotide kinase. A single "A" nucleotide was added to the $3^{\prime}$ ends of the blunt DNA fragments using a Klenow fragment ( $3^{\prime}$ to $5^{\prime}$ exo minus) enzyme. The cDNA fragments were ligated to double stranded adapters using T4 DNA ligase. The ligated products were enriched by PCR amplification $\left[30 \mathrm{~s}\right.$ at $98^{\circ} \mathrm{C} ;\left(10 \mathrm{~s}\right.$ at $98^{\circ} \mathrm{C}, 30 \mathrm{~s}$ at $60^{\circ} \mathrm{C}, 30 \mathrm{~s}$ at $\left.72^{\circ} \mathrm{C}\right) \times 14$ cycles; $5 \mathrm{~min}$ at $72^{\circ} \mathrm{C}$. Then, surplus PCR primers were removed by purification using AMPure XP beads (Agencourt Biosciences). DNA libraries were checked for quality and quantified using the 2100 Bioanalyzer (Agilent). The libraries were loaded in the flow cell at 7 pM concentration, and clusters were generated in the Cbot and sequenced in the Illumina Hiseq 2500 as single-end 50 base reads. Image analysis 

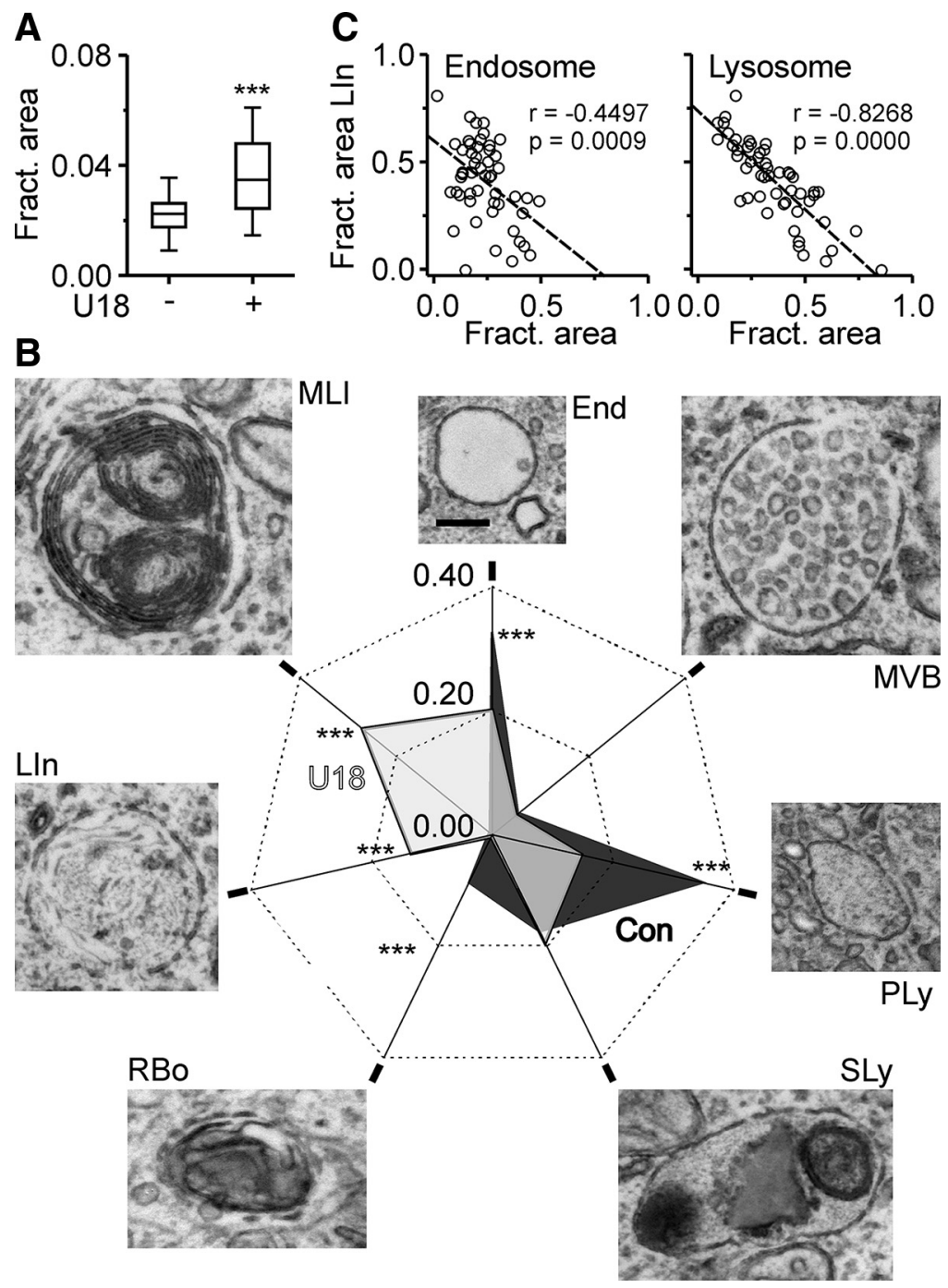

Figure 4. Impact of U18 on the endosomal-lysosomal system of neurons. $\boldsymbol{A}$, Fractional area of endosomes, lysosomes, and lamellar inclusions compared to total cell area in RGCs cultured in the absence ( $n=41$ cells) or presence of U18 ( $n=52 ; 3$ preparations; Mann-Whitney $U$ test). $\boldsymbol{B}$, Fractional area and representative transmission electron micrographs of indicated endosomal-lysosomal compartments in RGCs [ control (Con), black, $n=41$ cells; U18, gray, $n=52$ cells; Mann-Whitney U test]. End, Endosome; MVB, multivesicular body; PLy, primary lysosome; SLy, secondary lysosome; RBo, residular body; LIn, lamellar inclusion; MLI, multilamellar inclusion. Scale bar, $200 \mathrm{~nm}$. C, Fractional area of lamellar inclusions compared to total area of the endosomallysosomal system plotted against fractional area of endosomal (left) and of lysosomal compartments (right) in individual U18treated RGCs ( $n=51$; Pearson's correlation coefficients; $p$ values). Dashed lines indicate the linear regression fit. ${ }^{* * *} p<0.001$.

and base calling were performed using Real-Time Analysis version 1.17.21.3 and CASAVA version 1.8.2. Reads were mapped onto the mm10 assembly of the mouse genome using Tophat version 2.0.10 and the Bowtie version 2.1.0 aligner. Only uniquely aligned reads were retained for further analyses. Gene expression was quantified using HTSeq version 0.5.4p3 (Anders et al., 2015) and gene annotations from Ensembl release 74. Read counts were normalized across libraries as proposed previously (Anders and Huber, 2010). Comparison between NPC and WT samples was performed as described previously (Love et al., 2014) implemented in the DESeq2 Bioconductor library (version 1.0.19), adjusting for litter effects. Adjustment for multiple testing was performed with the method used by Benjamini and Hochberg (1995). Gene ontology and pathway analysis were performed using the Database for Annotation, Visualization and Integrated Discovery (version 6.7; Huang et al., 2009), using all Gene Ontology (GO) terms for biological process, cellular component, and molecular function, and thresholds for gene count $(\geq 3)$ and statistical significance [EASE (Expression Analysis Systematic Explorer) score $<0.05 ; p<0.05$ Benjamini-Hochberg corrected $t$ test].
Statistical analysis. Unless stated otherwise, statistical analyses were performed using the two-tailed multiple comparisons KruskalWallis test (Statistica 12; Dell/StatSoft). Levels of significance are indicated by asterisks in the figure legends. Box plots indicate percentiles of data distributions (boxes: 25, 50, and 75\%; whiskers: 5 and 95\%). Column plots indicate the means and whiskers the SDs.

\section{Results}

To provoke pathologic lipid accumulation in neurons, we treated serum-free cultures of purified RGCs (Fig. 1A) with the amphiphilic cation U18, which induces the cellular phenotype of NPC disease (Liscum and Faust, 1989; Karten et al., 2002) by blocking NPC1 activity (Lu et al., 2015). Treatment with U18 for $48 \mathrm{~h}$ induced the presence of filipinpositive puncta in neuronal somata in a dose-dependent manner, but decreased neuronal viability only at the highest concentration tested (Fig. $1 B, C$ ). Filipin-positive puncta occurred in the absence or presence of GCM (Fig. 1D), indicating accumulation of endogenous and imported cholesterol, respectively.

\section{Identification of lamellar inclusions as sites of cholesterol accumulation}

Next, we searched for the subcellular location of U18-induced cholesterol accumulation in neurons. TEM revealed the presence of round, often vacuolar structures of variable size inside neurons containing bits of electron-dense material in U18-treated $(0.5 \mu \mathrm{g} / \mathrm{ml}, 48 \mathrm{~h})$ RGCs (Fig. 1E, left), which were absent from untreated controls. To test, whether the vacuolar appearance was due to lipid loss during sample preparation, we treated cells with imidazole, which enhances lipid fixation by osmium tetroxide (Angermüller and $\mathrm{Fa}$ himi, 1982). The modified fixation protocol revealed the presence of membraneous lamellae inside the structures (Fig. 1E, middle). Prior staining of cells with filipin strongly increased the electron density of the lamellae probably by enhancing osmium complexation (Fig. 1E, right), indicating that lamellar inclusions contain unesterified cholesterol. Next, we investigated whether filipin-cholesterol-osmium complexes can be visualized in intact cells by scanning electron microscopy combined with BSE detection. Scanning electron microscopy revealed the presence of filipin-osmium-stained cholesterol-rich inclusions inside U18-treated RGCs, but not in untreated neurons or in neurons that were not stained with filipin (Fig. $1 F$ ). Next, we performed correlative light and electron microscopy (CLEM), which traces the ultrastructural correlate of fluorescently labeled structures (Sjollema et al., 2012). This approach provided direct evidence that the cholesterol-containing lamellar inclusions observed by TEM correspond to filipin- 
A
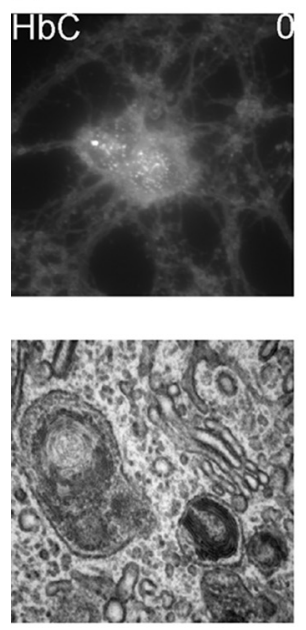
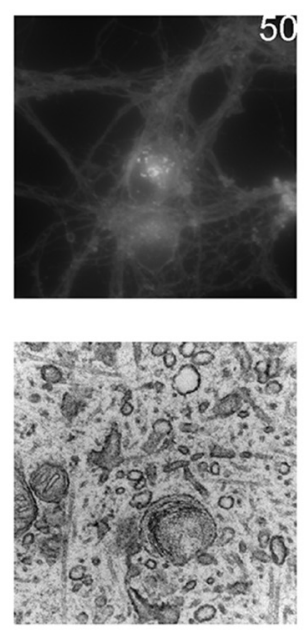

B
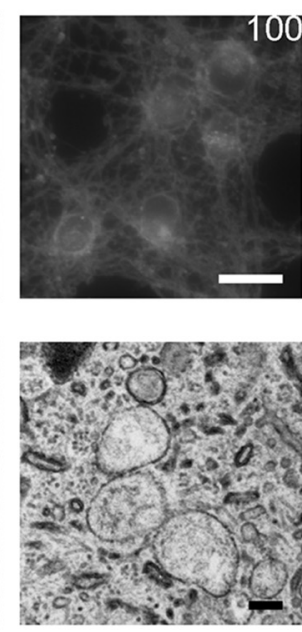

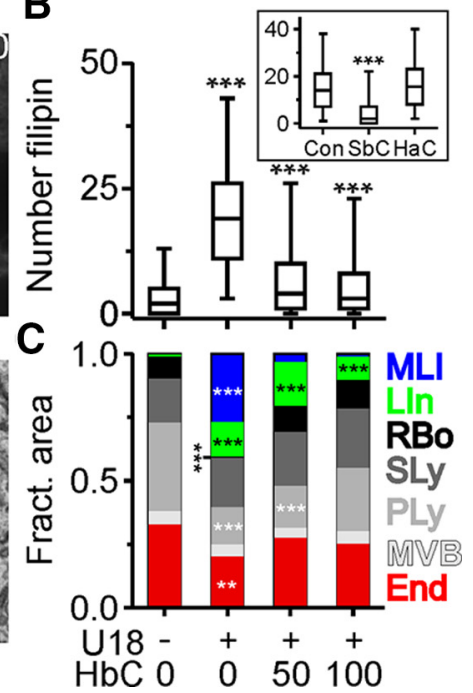

Figure 5. $\mathrm{HbC}$-induced reversal of cholesterol accumulation in lamellar inclusions. $\boldsymbol{A}$, Fluorescence and electron micrographs showing filipin distribution (top) and ultrastructure (bottom) of RGCS treated with $\mathrm{U} 18$ and for the last $24 \mathrm{~h}$ with $\mathrm{HbC}$ at indicated concentrations (in micromolar). Scale bars: top, $20 \mu \mathrm{m}$; bottom, $200 \mathrm{~nm}$. B, Number of filipin-positive puncta in somata of RGCs treated with U18 and with HbC [control (Con), $n=410$ cells; U18, $n=548 ; U 18+50 \mu \mathrm{m} \mathrm{HbC,} n=470 ; \mathrm{U} 18+100 \mu \mathrm{m} \mathrm{HbC}, n=450 ; 5$ preparations] or with SbC (100 $\mu \mathrm{m}$ ) and HaC (100 $\mu \mathrm{m}$; inset, control treated with U18, $n=490$ cells; SbC, $n=211$ cells; $\mathrm{HaC}, n=366$ cells; 3 preparations). C, Average fractional area of endosomal-lysosomal compartments in RGCs treated as indicated (Con, $n=$ 41 cells; U18, $n=52$ cells; U18 $+50 \mu \mathrm{m} \mathrm{HbC,} n=46$ cells; U18 $+100 \mu \mathrm{m} \mathrm{HbC,} n=45$ cells; 3 preparations). ${ }^{* *} p<0.01 ;{ }^{* *} p<0.001$.

positive puncta revealed by fluorescence microscopy $(n=5$ cells; Fig. 1G).

\section{Accumulation of surface-resident GM1 in cholesterol-rich inclusions}

U18 treatment and NPC1 dysfunction cause intracellular accumulation of lipids other than cholesterol (Lloyd-Evans et al., 2008), namely, gangliosides (Sugimoto et al., 2001; Zervas et al., 2001). We therefore studied the distribution of ganglioside GM1, an essential component that controls the structural and functional properties of the neuronal plasma membrane (Ledeen and $\mathrm{Wu}, 2015)$. To this end, we took advantage of the fact that surface-resident GM1 can be labeled in living cells by CTB. Incubation of RGCs with CTB for increasing periods of time labeled first the plasma membrane and then intracellular structures due to constitutive endocytosis of GM1 (Fig. 2A,C). In the presence of U18, CTB-labeled GM1 from the cell surface was incorporated into cholesterol-rich lamellar inclusions within 24 to $48 \mathrm{~h}$, as shown by colocalization with filipin (Figs. $2 A-C$ ) and TEM $(D)$.

\section{Endosomal-lysosomal origin of lamellar inclusions}

Having identified lamellar inclusions as the subcellular site of lipid accumulation, we investigated their relation to the endosomal-lysosomal system, which is the primary target of U18 treatment and NPC1 deficiency (Sokol et al., 1988; Liscum and Faust, 1989). Immunocytochemical staining revealed that U18 enhanced the number of CD63-positive but not of LAMP1positive puncta in neuronal somata and induced colocalization of both markers with filipin-positive puncta (Figs. $3 A, B$ ). Immunogold labeling and TEM of U 18-treated RGCs revealed the presence of LAMP1 and CD63 in lamellar inclusions (Fig. 3C). Notably, LAMP1 (Fig. 3C, filled arrowheads) decorated exclusively the membrane surrounding the inclusions, whereas CD63 (empty arrowheads) was restricted to internal lamellae indicating distinct origins of these membrane compartments.
Next, we determined the impact of U18 on the endosomal-lysosomal system by quantitative TEM. Our analysis revealed that U18 enlarged the size of the endosomal-lysosomal system in RGCs (Fig. $4 A$ ), induced lamellar inclusions, and reduced the contribution of endosomes, primary lysosomes, and residual bodies to the total endosomal-lysosomal system (Fig. 4B). The fractional area of lamellar inclusions was negatively correlated with that of endosomes and of primary lysosomes (Fig. $4 C$ ), suggesting that the inclusions formed at the expense of these compartments.

\section{Cyclodextrin-mediated reversal of cholesterol accumulation by exocytotic release of inclusions}

At present, there is no curative treatment for NPC disease, but $\mathrm{HbC}$, a modified $\beta$-cyclodextrin, slows down neurodegeneration in animal models of the disease (Liu et al., 2009a; Davidson et al., 2009; Aqul et al., 2011; Vite et al., 2015). To clarify the mechanism of action in neurons, we studied the effect of cyclodextrins on RGCs. Within $24 \mathrm{~h}$ of treatment, $\mathrm{HbC}$ reverted the U18-induced accumulation of cholesterol in lamellar inclusions and the changes to the endosomal-lysosomal system in a dose-dependent manner (Fig. 5). The reversal was mimicked by SbC, a sulfobutylether derivative of $\beta$-cyclodextrin (Ramirez et al., 2011; Taylor et al., 2012; Davidson et al., 2016), but not by HaC (Fig. 5B), probably because the cavity of $\alpha$-cyclodextrins is too small to harbor cholesterol (Zidovetzki and Levitan, 2007; Gimpl, 2010).

Scanning electron microscopic inspection of RGCs that were treated with $\mathrm{U} 18$ and $\mathrm{HbC}$ and labeled with filipin and immunogold revealed the occasional presence of cholesterol-rich inclusions at the cell surface that were surrounded by a LAMP1positive rim of plasma membrane (Fig. $6 A, B$ ). This surprising finding suggested that $\mathrm{HbC}$ induces the neuronal release of lamellar inclusions. To address this point, we performed immunogold labeling of nonpermeabilized RGCs. Scanning electron microscopy combined with BSE detection revealed that $\mathrm{HbC}$ increased the density of LAMP1, but not of CD63 on the neuronal surface (Fig. $6 C, D$ ). This effect occurred only in U18-treated cells, but not in untreated controls (Fig. 6D). Regardless of the treat- 
A

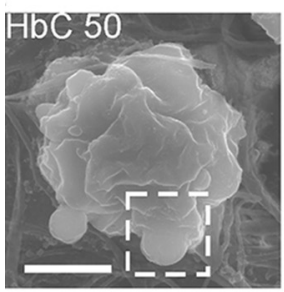

C
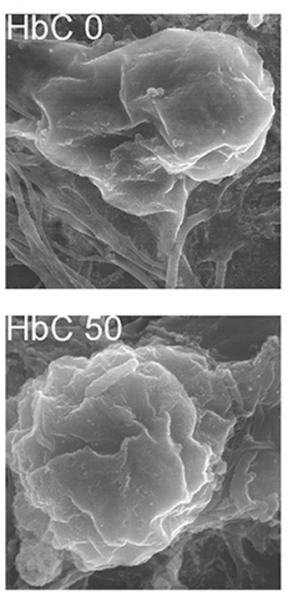

E

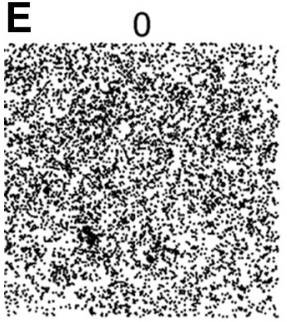

G

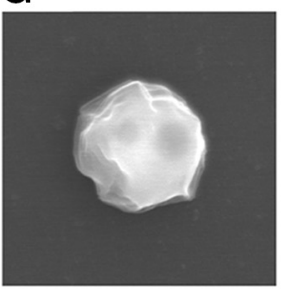

H

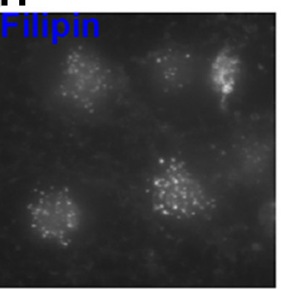

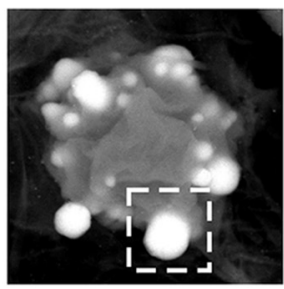
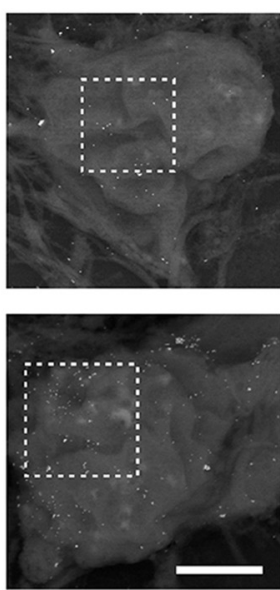

50

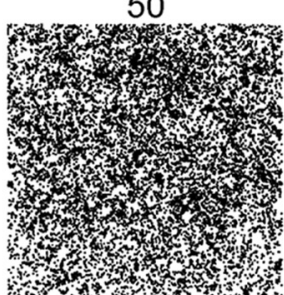

Hothos
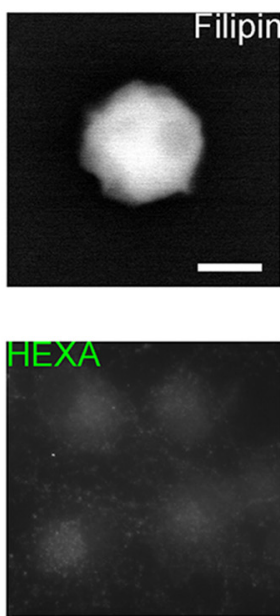

B
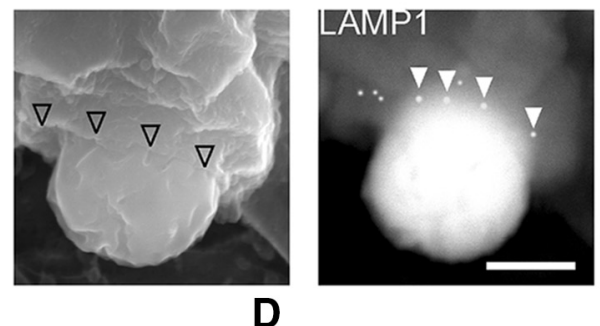

D
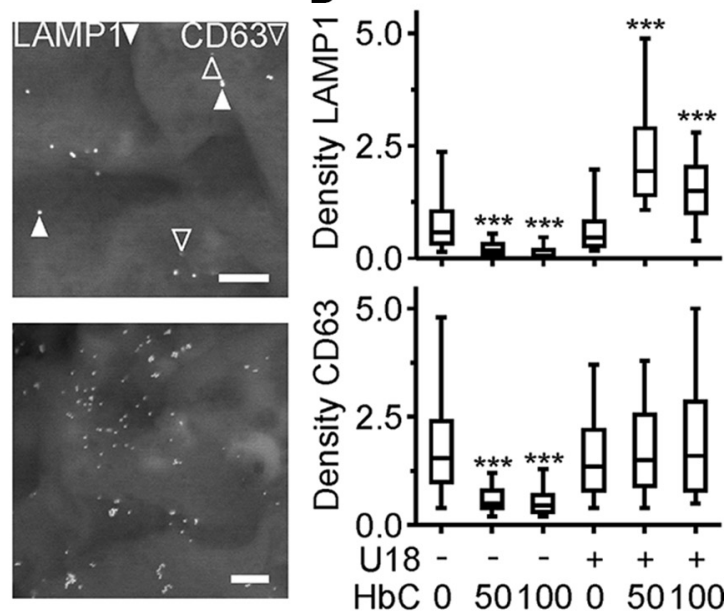

$F$
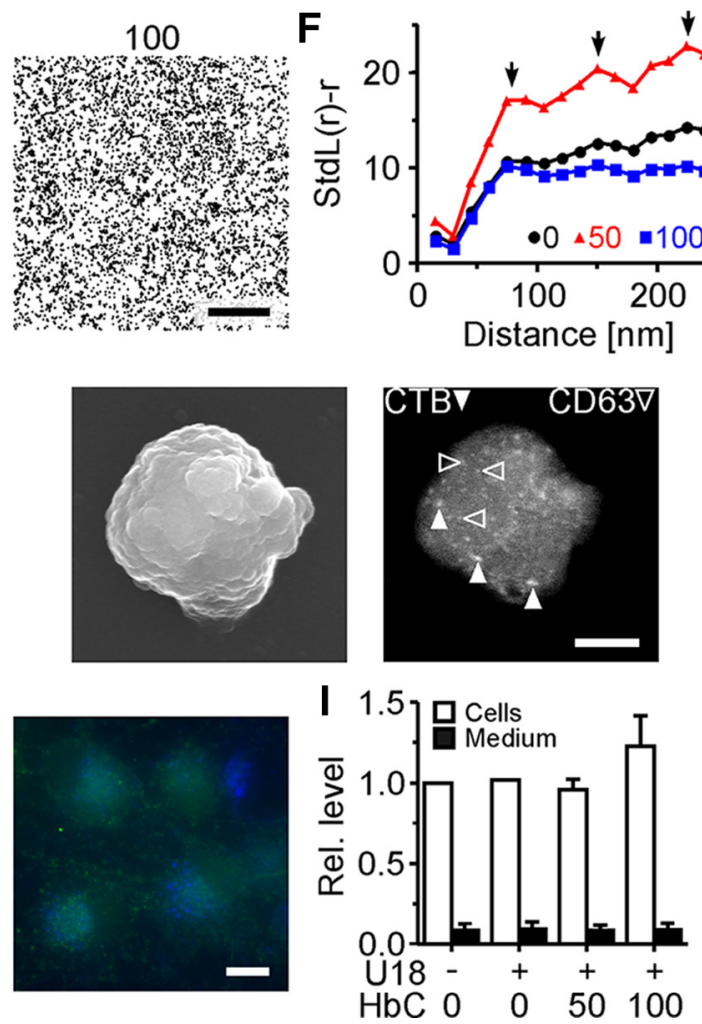

Figure 6. $\mathrm{HbC}$-induced release of lamellar inclusions from neurons. $\boldsymbol{A}$, Scanning electron micrographs (left, secondary electron; right, BSE) of an RGC treated with U18 and $\mathrm{HbC}(50 \mu \mathrm{M}$ ), stained with filipin, and immunogold labeled with an antibody against LAMP1 without prior permeabilization. $\boldsymbol{B}$, Higher-magnification images of the area outlined in $\boldsymbol{A}$ showing a filipin-0smium-stained, cholesterol-rich inclusion leaving the soma with the rim of the plasma membrane (left, secondary electron; empty arrowheads) decorated by LAMP1 (right, BSE; filled arrowheads). C, Scanning electron micrographs (left, secondary electron; middle, right, BSE) of RGCs treated with U18 and with HbC at indicated concentrations and subjected to immunogold labeling of LAMP1 (40 nm; filled arrowheads) and CD63 (25 nm; empty arrowheads) without prior cell permeabilization. D, Densities (per square micrometer) of indicated proteins on the surface of nonpermeabilized RGCs after indicated treatments ( $n=104$ cells per condition; 4 preparations). $\boldsymbol{E}$, Pooled distributions of immunogold-labeled LAMP1 on the plasma membrane of RGCs treated with U18 and with HbC at indicated concentrations (in micromolar; U18, $n=8863$ particles; U18 + CD50, $n=16253$ particles; U18 + CD100, 7483 particles; for each condition, particles were pooled from data shown in $\boldsymbol{D}$ ). $\boldsymbol{F}$, Analysis by Ripley's $k$ function indicating a clustered surface distribution of LAMP1 on RGCs with an estimated

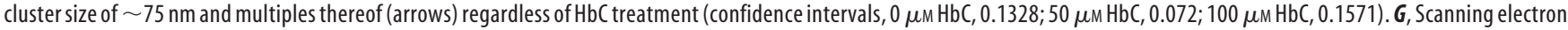
micrographs of structures detected in sediment of culture medium from U18- and HbC-treated (100 $\mu \mathrm{m})$ RGCs. The structures were of similar size (Figure legend continues.) 
ment, the distribution of LAMP1 in the plasma membrane was clustered (Fig. 6E,F).

Further evidence for the HbC-induced release of inclusions was obtained by scanning electron microscopy imaging of sediment from neuron-conditioned medium. In medium from $\mathrm{HbC}-$ and U18-treated cells, we observed structures that were of similar size as lamellar inclusions and that contained filipin-osmiumstained cholesterol as well as CTB-labeled GM1 and CD63 (Fig. $6 G$ ). We could not detect a $\mathrm{HbC}$-induced increase in hexosaminidase activity in the medium nor colocalization of filipin-stained cholesterol and hexosaminidase in neurons (Fig. $6 H, I$ ) suggesting the absence of this lysosomal enzyme from U18-induced inclusions.

To further investigate the exocytotic release of inclusions, we examined the cytoplasmic face of the neuronal plasma membrane using a cell fracturing technique in combination with scanning electron microscopy (Fig. 7A). This approach revealed that $\mathrm{HbC}$ strongly enhanced the number of U18-induced cholesterolrich inclusions attached to the cytoplasmic side of the plasma membrane (Fig. 7 B, C). The surface density of LAMP1 (Fig. 6D) and the subplasmalemmal density of inclusions showed remarkably similar dose dependency (Fig. 7C). Immunogold labeling of fractured RGCs combined with scanning electron microscopy revealed an association of subplasmalemmal inclusions with tubulin, actin (Fig. 7B), and VAMP8 (Fig. 7D).

\section{Effects of NPC1 deficiency on RGCs and their reversal by HbC ex vivo}

Based on the results obtained with U18 treatment, we studied the impact of NPC1 deficiency on neurons and the effects of HbC. To this end, we established an ex vivo preparation of RGCs that were acutely isolated from retinae of 1-week-old BALB/c mutant mice. With older animals, the purity of the preparation decreased significantly (Fig. 8A). First, we took advantage of this model to define the neuron-specific reaction to NPC1 deficiency using gene expression profiling by high-throughput RNA sequencing (Gene Expression Omnibus accession number GSE75775). Mutant mice showed lower transcript counts than their wild-type littermates (Fig. 8B), and the profiling proved highly reproducible across biological replicates $(n=4$ mice per genotype; Fig. $8 C, D)$. Comparison of transcript counts revealed a limited number of genes that are upregulated $(n=$ $75)$ and downregulated $(n=191)$ in RGCs acutely purified from mutant mice $(n=4)$ compared to those from wild-type littermates $(n=4$; Fig. $8 E)$. Transcript counts of $N p c 1$ and the neuronal marker Calb1 were reduced in RGCs from mutant mice compared to wildtype littermates (Fig. $8 F$ ) as expected based on previous studies (Loftus et al., 1997; German et al., 2001; Claudepierre et al., 2010), thus validating our approach. The observed changes at transcript levels also affected protein levels as shown for ARHGAP9, one of the most strongly downregulated genes (Fig. 8G). GO term analysis revealed increased transcript counts for genes involved in cholesterol and

\section{$\leftarrow$}

(Figure legend continued.) as lamellar inclusions, and contained filipin-osmium-stained cholesterol (left pair, secondary electrons and BSE images) and CTB-labeled GM1 (filled arrowheads) and CD63 (empty arrowheads; right pair, secondary electron and BSE images). $\boldsymbol{H}$, Fluorescence micrographs of RGCs treated with U18 and subjected to filipin staining (left) and to immunocytochemical staining with an antibody against hexosaminidase A (middle). Right, False-color micrograph showing little overlap between filipin-positive puncta (blue) and hexosaminidase A label (green, intensity enhanced). $I$, Hexosaminidase activity in RGCs (white) and in RGC-conditioned medium (black) in the presence or absence of $\mathrm{U} 18$ and $\mathrm{HbC}$. Levels were normalized to activity in untreated control cells $\left(\mathrm{n}=3\right.$ preparations). ${ }^{* * *} p<0.001$. Scale bars: $\boldsymbol{A}, 3 \mu \mathrm{m} ; \boldsymbol{B}, 750 \mathrm{~nm}$; $\boldsymbol{C}$, left, middle, $3 \mu \mathrm{m}$; right, $500 \mathrm{~nm} ; \boldsymbol{E}, 2 \mu \mathrm{m} ; \boldsymbol{G}, 750 \mathrm{~nm} ; \boldsymbol{H}, 20 \mu \mathrm{m}$.
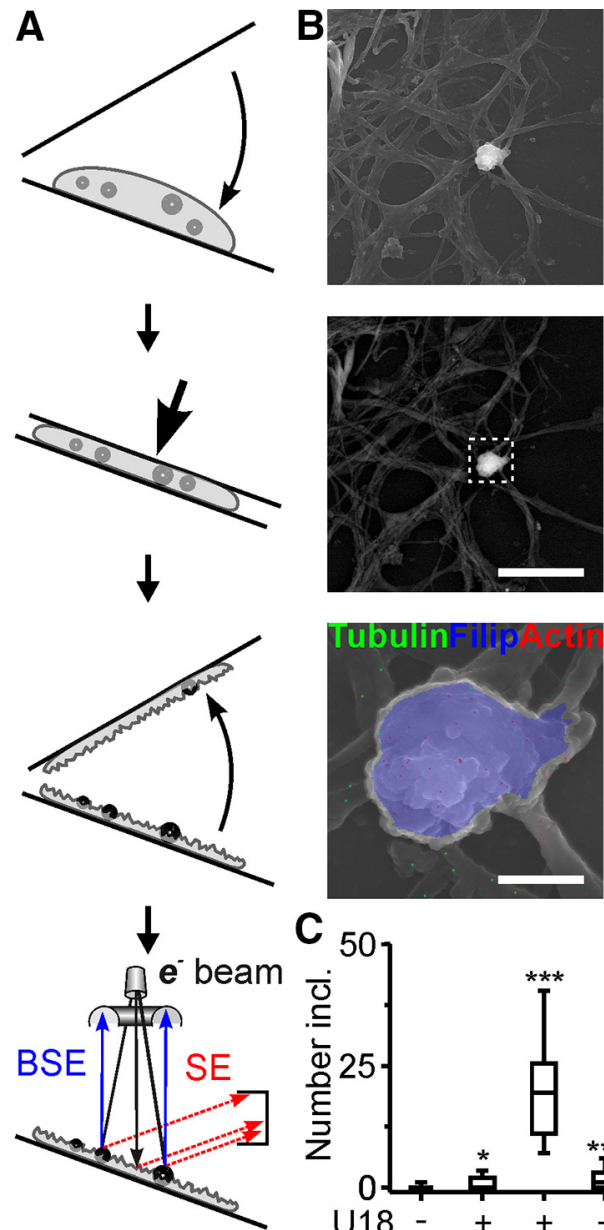

D
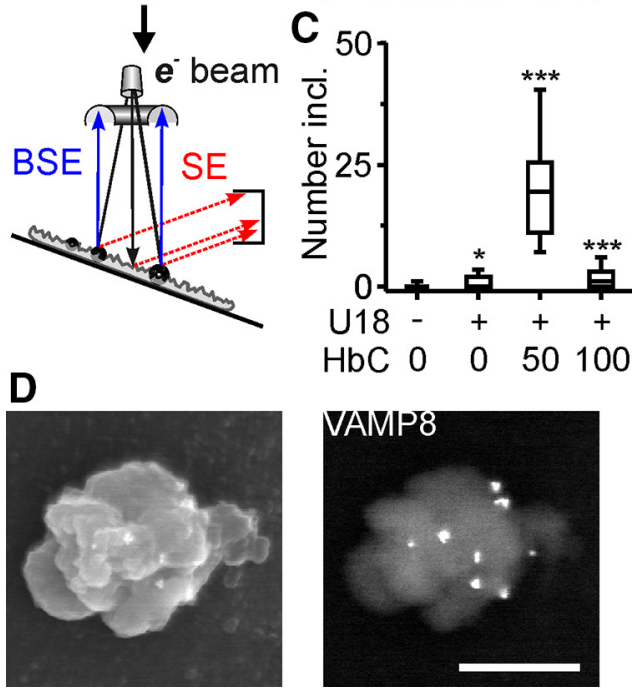

Figure 7. $\mathrm{HbC}$-induced accumulation of lamellar inclusions at the cytoplasmic face of the plasma membrane. $\boldsymbol{A}$, Diagrams illustrating horizontal cell fracturing and scanning electron microscopy with secondary electron and BSE detection to visualize the cytoplasmic face of the neuronal plasma membrane. $\boldsymbol{B}$, Scanning electron micrographs (top, secondary electron; middle, bottom, BSE) showing the cytoplasmic face of the plasma membrane after fracturing of an U18- and HbC-treated RGC. Bottom, High-magnification false-color image of outlined area showing an inclusion with overlay of secondary electron (gray scale) and BSE signals (color) after filipin staining (blue) and immunogold labeling to reveal tubulin (green) and actin (red). C, Number of cholesterol-rich inclusions at the cytoplasmic face of the plasma membrane under indicated conditions ( $n=100$ cells per condition; 4 preparations). D, Scanning electron micrographs of an U18- and $\mathrm{HbC}$-treated (100 $\mu \mathrm{m})$ RGC after cell fracturing (left, secondary electron; right, BSE). Note the cholesterol-rich inclusion at the cytoplasmic face of the plasma membrane covered with immunogold labeled clusters of VAMP8. Scale bars: $\boldsymbol{B}$, top, middle, $10 \mu \mathrm{m}$; bottom, 1.5 $\mu \mathrm{m} ; \boldsymbol{D}, 1 \mu \mathrm{m} .{ }^{*} p<0.05 ;{ }^{* * *} p<0.001$.

fatty acid synthesis and in lipoprotein accretion and decreased counts for those mediating cholesterol efflux in RGCs from mutant mice compared to wild-type controls (Fig. 8H,I). These findings suggested that already at 1 week of age, NPC1-deficient neurons experience a cholesterol deficit in the endoplasmic reticulum because of its accumulation in the endosomal-lysosomal system. 
A
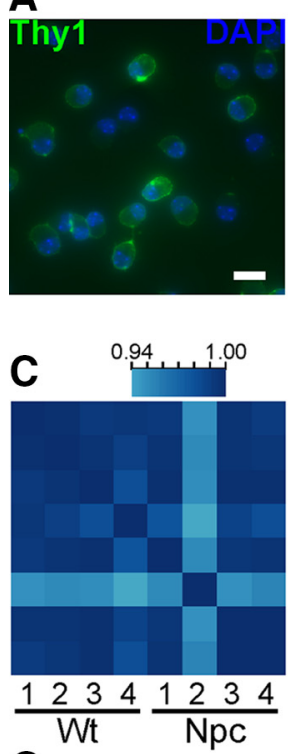

G
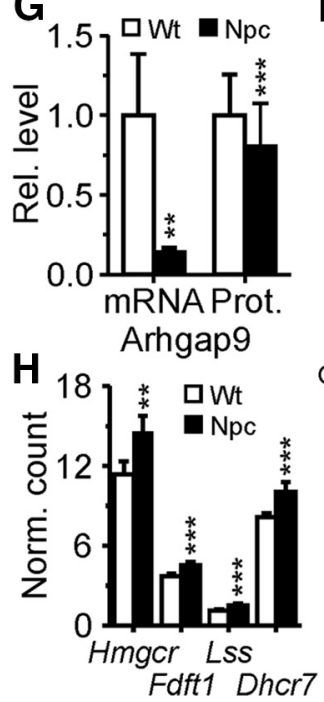

I Fdft1 Dhor7

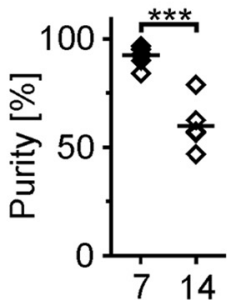

B

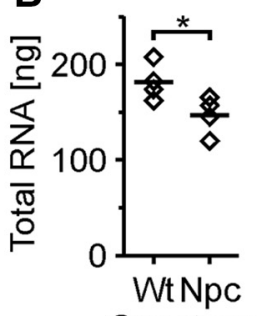

Age [d]

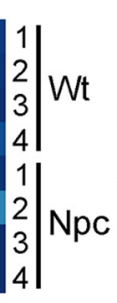

D

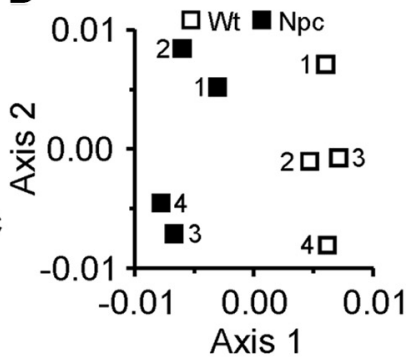

E

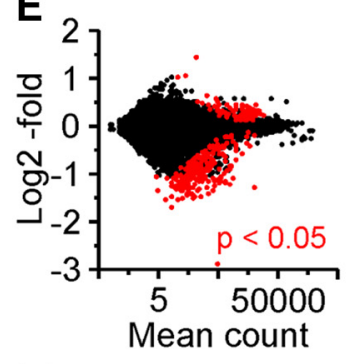

$F$

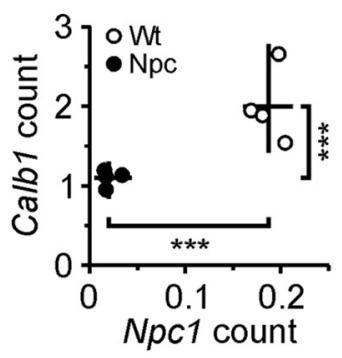

GO:0016126 sterol biosynthetic process GO:0006629 lipid metabolic process GO:0005783 endoplasmic reticulum GO:0006633 fatty acid biosynth. process GO:0005739 mitochondrion

GO:0002376 immune system process GO:0006935 chemotaxis GO:0042127 regulation of cell prolif. GO:0001664 G-prot.-coupl. recept. binding GO:0048514 blood vessel morphogenesis GO:0005125 cytokine activity GO:0033344 cholesterol efflux. GO:0003700 transcription factor activity GO:0009416 response to light stimulus GO:0019226 transm. of nerve impulse

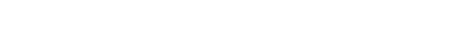

Figure 8. Gene expression profiling by RNAseq of RGCs acutely purified from wild-type and NPC1-deficient mice. $A$, Left, false-color micrographs of RGCS acutely purified from 1-week-old mice by immunopanning and subjected to nuclear staining with DAPI (blue) and to immunocytochemical staining for Thy1 (green). Scale bar, $20 \mu \mathrm{m}$. Right, percentage of Thy $1+$ cells after isolation from retinae of 1-week-old $(n=9)$ and 2-week-old mice $(n=5 ; t$ test). Immunopanning delivered $\sim 73,000 \pm 8,000$ Thy1-positive cells per 1-week-old mouse $(n=5)$. B, Quantity of total RNA in purified RGCs per mouse ( $n=4$ mice per genotype corresponding to biological replicates; $t$ test). $C$, Heat map of Pearson's correlation coefficient showing the reproducibility of transcript counts among biological replicates. $\boldsymbol{D}$, First factorial plane resulting from a correspondence analysis of variance-stabilized data with the $x$-axis and $y$-axis explaining 23 and $22 \%$ of the variability of the whole dataset, respectively. $\boldsymbol{E}$, Mean fold changes of transcript counts in RGCs from 1-week-old mutant mice compared to wild-type littermates plotted against normalized mean counts of each transcript as revealed by RNAseq. Red dots indicate genes with an adjusted $p$ value of $<0.05$. $F$, Counts of indicated transcripts divided by gene lengths in RGCs from individual mice as indicated (lines indicate means). $G$, Means of relative transcript counts and relative fluorescence intensities of ARHGAP9 revealed by RNAseq ( $n=4$ per genotype; $t$ test) and by immunocytochemical staining of acutely isolated RGCS, respectively (WT, $n=443$ cells; NPC, $n=492$ cells; 3 preparations; Mann-Whitney $U$ test). $\boldsymbol{H}$, Transcript counts divided by gene lengths of selected cholesterol-synthesizing enzymes in purified RGCs revealed by RNAseq ( $n=4$ per genotype; values divided by 1000). $I$, Enrichment of gene ontology terms (numbers of genes per G0 term) in transcripts of RGCs from mutant mice compared to wild-type littermates ( $n=4$ mice per genotype). Unless indicated otherwise, $p$ values are from $t$ tests adjusted by the Benjamini-Hochberg method. ${ }^{*} p<0.05$; ${ }^{* *} p<0.01$; ${ }^{* * *} p<0.001$.

Indeed, filipin staining, immunocytochemistry, and scanning electron microscopy combined with BSE imaging revealed filipinpositive structures that colocalized with LAMP1 in RGCs from 1-week-old mutant mice, but not in wild-type littermates (Fig.

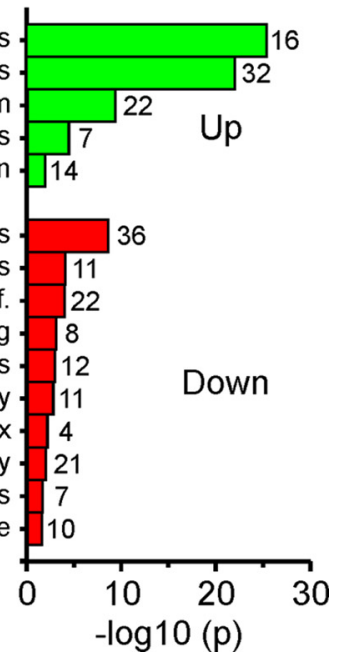

$9 A, B)$. TEM inspection of filipin-stained neurons confirmed the presence of inclusions with electron-dense lamellae (Fig. 9C). Our observation of cholesterol accumulation in our ex vivo preparation prompted us to test the effects of $\mathrm{HbC}$. Treatment of NPC1-deficient RGCs with $\mathrm{HbC}$ for 24 to $30 \mathrm{~h}$ reverted the intracellular accumulation of filipin-stained cholesterol and of LAMP1 and strongly increased the density of LAMP1 on the cell surface (Fig. 9A,B) indicating the release of cholesterol-rich inclusions. The release was further supported by the presence of filipin-osmium-stained structures still attached to the surface of $\mathrm{HbC}$-treated RGCs from mutant mice (Fig. 9D).

Closer inspection of HbC-treated RGCs from mutant mice by BSE imaging revealed the presence of inclusions within somata that were partially depleted of cholesterol (Fig. 9A, bottom). This observation suggested that $\mathrm{HbC}$ mediates the transfer of cholesterol from lamellar inclusions to the cell-intrinsic pools. To test this indirectly, we measured HMGCR levels in somata of RGCs from mutant mice. This experiment revealed a small but robust $\mathrm{HbC}$-induced reduction of somatic HMGCR levels in NPC1-deficient RGCs (Fig. 9E), indicating a redistribution of cholesterol to the endoplasmatic reticulum. Moreover, treatment with cholesterol $(10 \mu \mathrm{g} / \mathrm{ml} ; 24 \mathrm{~h})$ reduced HMGCR levels in RGCs from wild-type mice, but not in those from mutant littermates (Fig. 9E). This validated the downregulation of HMGCR levels by external cholesterol in normal RGCs and the impaired cholesterol transport in NPC1deficient neurons.

\section{Discussion}

Here, we provide new insight into the intracellular location, impact, and therapeutic reversal of pathologic lipid accumulation in neurons affected by NPC disease. Moreover, we deliver refined electron microscopic tools to visualize lipid aggregation in cells at nanoscale resolution.

By improved lipid fixation and CLEM, we identify lamellar inclusions as the subcellular sites of cholesterol accumulation in neurons with impaired NPC1 activity. This finding merges two hallmarks of NPC disease that are observed by light and electron microscopy: the intracellular accumulation of unesterified cholesterol in neurons (Yamada et al., 2001; Karten et al., 2002; Runz et al., 2002; Reid et al., 2004) and the presence of "lamellar bodies" or "myelin figures" in neurons of NPC patients (Harzer et al., 1978) and animal models (Tanaka et al., 1988; Lowenthal et al., 1990; Phillips et al., 2008). The 
A
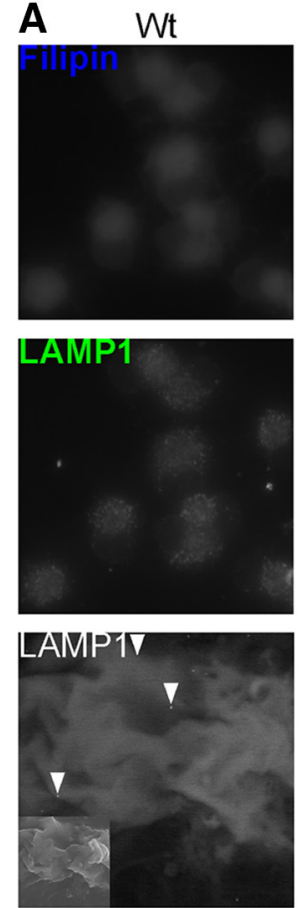

C

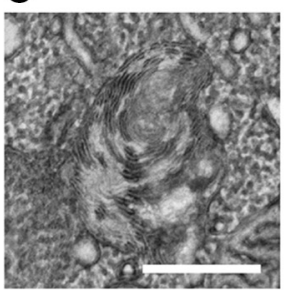

E

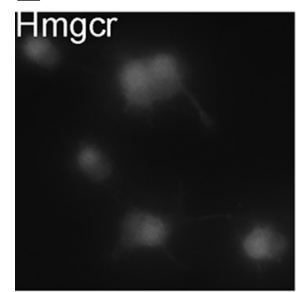

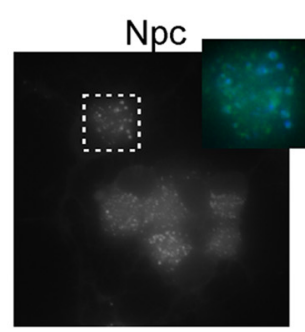
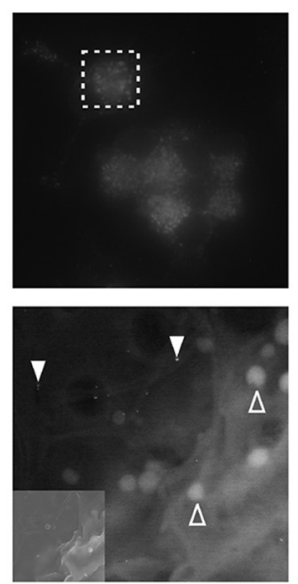

D
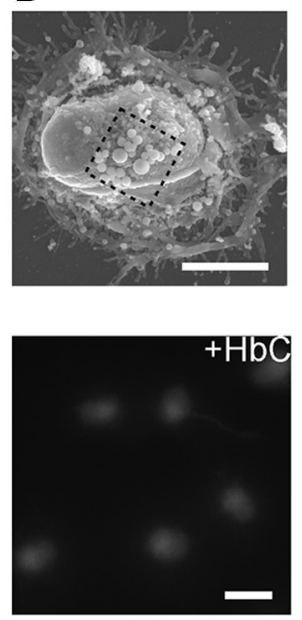

$\mathrm{Npc}+\mathrm{HbC}$
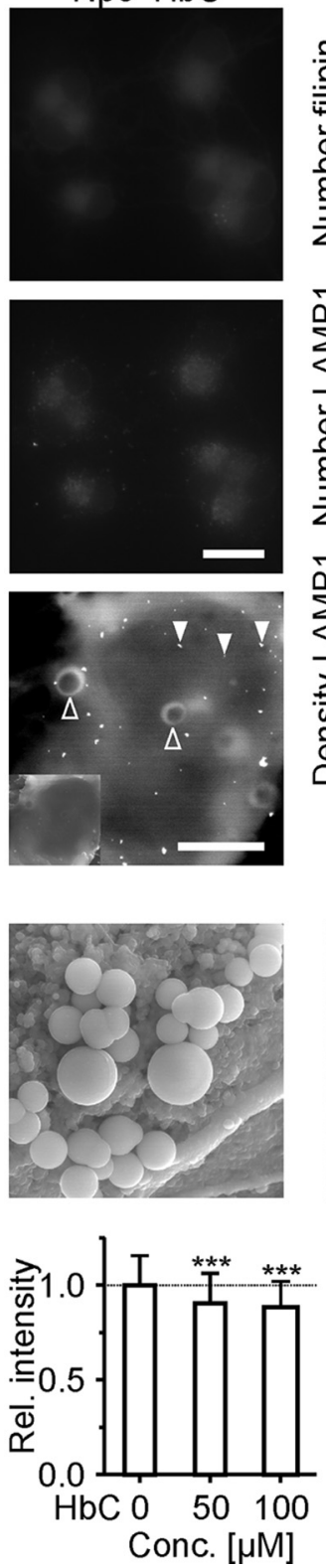

B
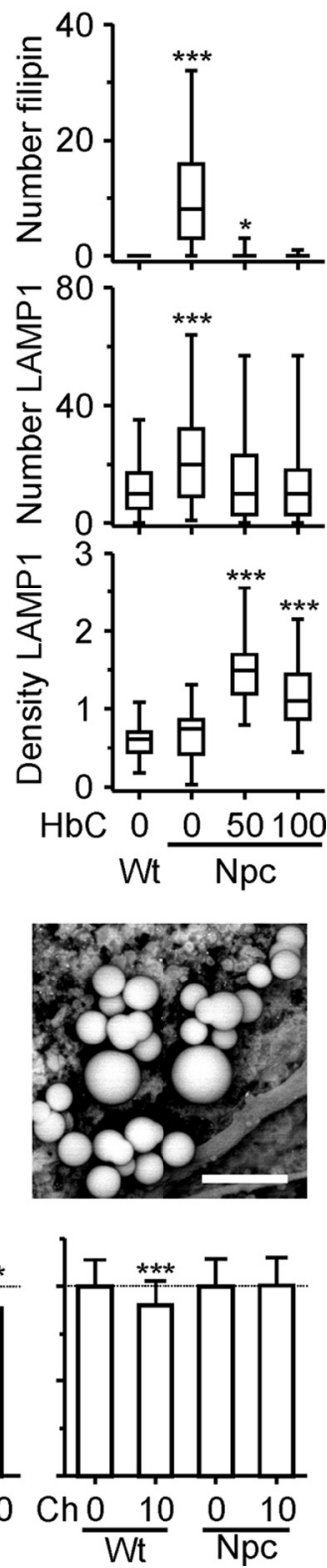

Figure 9. HbC-mediated reversal of cholesterol accumulation in RGCs acutely isolated from NPC1-deficient mice. A, Fluorescence (top, middle) and scanning electron micrographs (bottom, BSE images; insets, corresponding secondary electron images) of RGCs with indicated genotypes and treatments (100 $\mu \mathrm{m} \mathrm{HbC} \mathrm{for} 24-30 \mathrm{~h}$ ) subjected to filipin staining (top), to immunocytochemical staining of LAMP1 inside cells (middle; fluorescence), and to immunogold staining on the cell surface (bottom; BSE images). Top, False-color micrograph shows outlined area at higher magnification (blue, filipin; green, LAMP1; intensities modified). Bottom, Arrowheads indicate immunogold-labeled LAMP1 (filled) and filipin-osmium-stained cholesterol-rich inclusions (empty). Note the apparent partial depletion of cholesterol from inclusions after HbC treatment. B, Number of filipin-positive (top) and of LAMP1-positive puncta in RGC somata (middle) and surface density (bottom) of immunogold-labeled LAMP1 (per square micrometer) in nonpermeabilized RGCs after indicated treatments (WT, filipin, $n=674$ cells; LAMP1, $n=249$ cells; NPC, filipin, $n=838$ cells; LAMP1, $n=330$ cells; $50 \mu \mathrm{m} \mathrm{HbC}$, filipin, $n=220$ cells; LAMP1, $n=244$ cells; $100 \mu \mathrm{m} \mathrm{HbC}$, filipin, $n=234$ cells; LAMP1, $n=239$ cells; $n=2-4$ preparations; LAMP1 density, 50 cells per condition; 2 preparations). C, Representative transmission electron micrograph showing lamellar inclusions in an NPC1-deficient RGC acutely isolated and fixed with imidazole and filipin. D, Scanning electron micrographs (left, middle, secondary electron; right, BSE) of an NPC1-deficient RGC treated with $\mathrm{HbC}(100 \mu \mathrm{M})$ for $30 \mathrm{~h}$. Middle and right micrographs show the outlined area at higher magnification. Note the presence of filipin-osmium-stained cholesterol-rich inclusions on the cell surface after HbC-induced release. $E$, Left, Fluorescence micrographs of RGCs from 1-week-old NPC1-deficient mice, treated as indicated (100 $\mu \mathrm{M} \mathrm{HbC)} \mathrm{and} \mathrm{subjected} \mathrm{to} \mathrm{immuno-}$ cytochemical staining for HMGCR. Right, Relative HMGCR levels in somata of NPC1-deficient RGCs treated with HbC (left; $0 \mu \mathrm{m}, n=308$ cells; $50 \mu \mathrm{m}, 258$ cells; $100 \mu \mathrm{m}, 276$ cells; 3 preparations) and RGCs from wild-type and mutant mice treated with cholesterol (right; WT, $0 \mu \mathrm{g} / \mathrm{ml}, 456$ cells; $10 \mu \mathrm{g} / \mathrm{ml}, 459$ cells; NPC, $0 \mu \mathrm{g} / \mathrm{ml}, 375$ cells; $10 \mu \mathrm{g} / \mathrm{ml}, 391$ cells; 4 preparations; Mann-Whitney $U$ test). Scale bars: $\boldsymbol{A}$, top, middle, $20 \mu \mathrm{m}$; bottom, $3 \mu \mathrm{m} ; \boldsymbol{C}, 500 \mathrm{~nm}$; $\boldsymbol{D}$, left, $12 \mu \mathrm{m}$; middle, right, $3 \mu \mathrm{m} ; \boldsymbol{E}, 20 \mu \mathrm{m}$. ${ }^{*} p<0.05$; ${ }^{* * *} p<0.001$.

vacuolar appearance of NPC1-deficient neurons (Harzer et al., 1978; Liao et al., 2007) may have been caused by lipid loss after conventional fixation of TEM samples. A previous report showed that $\mathrm{U} 18$ binds directly to NPC1 and blocks its activity (Lu et al., 2015). This finding explains why U18 mimics the cellular phenotype of NPC1 deficiency and suggests that lamellar inclusions induced by drug treatment are comparable to those caused by NPC1 deficiency.

Two independent lines of evidence indicate that lamellar inclusions originate from the endosomal-lysosomal system: Our 
quantitative TEM analysis revealed that their fractional area in individual neuronal somata was inversely proportional to the area of endosomes and lysosomes. Our immunogold labeling defined the origin of their membrane compartments: The presence of LAMP1 on their surrounding membrane indicated that they are late endosome/lysosome-derived or endosome/ lysosome-related organelles (Marks et al., 2013). The absence of hexosaminidase suggests that they are distinct from mature lysosomes. The internal lamellae were decorated by CD63, indicating that they originate from intraluminal vesicles of late endosomes (Pols and Klumperman, 2009). The exact mechanism, by which lamellae form, remains to be determined, but the endosomallysosomal origin of inclusions further validates them as site of cholesterol accumulation.

Our finding that lamellar inclusions form in the absence of external lipoproteins indicates that impaired activity of NPC1 causes accumulation of neuron-intrinsic cholesterol. This observation is in line with reports on different types of NPC1deficient cells including neurons (Karten et al., 2002; Reid et al., 2003). A likely source is the plasma membrane, as suggested by previous reports on U18-treated or NPC1-deficient cells showing transfer of cholesterol from the cell surface to lysosomal compartments (Lange et al., 1998). Labeling surface-resident GM1 in living neurons with CTB revealed that this key component of the neuronal plasma membrane becomes trapped in lamellar inclusions during treatment with U18. Thus, inhibition of NPC1 may cause a slow but steady depletion of lipids and other components from the neuronal plasma membrane. This depletion may compromise membrane-dependent signaling processes such as neurotrophin responsiveness, as shown for NPC1-deficient neurons in vitro (Henderson et al., 2000).

Our neuron-specific transcript analysis suggests an upregulation of cholesterol synthesis and uptake and the downregulation of its release in NPC1-deficient neurons already at 1 week of age. These changes were caused by cholesterol accumulation in lamellar inclusions leading to a deficit in the endoplasmatic reticulum (Goldstein et al., 2006). Enhanced cholesterol synthesis in NPC1deficient neurons has not been reported so far. Measurements of cholesterol synthesis in whole brain extracts from NPC1deficient mice and wild-type controls (Xie et al., 1999; Repa et al., 2007) cannot detect cell-specific changes, and the presence of serum may perturb the properties of NPC1-deficient neurons (Karten et al., 2002). Moreover, this effect is likely to be absent in U18-treated neurons, because the drug also inhibits cholesterol synthesis (Cenedella, 2009). Overall, we hypothesize that a slow but steady depletion of components from the plasma membrane and a gradual intracellular overload with cholesterol and other molecules produced along the synthesis pathway contribute to the dysfunction and degeneration of specific types of neurons in NPC disease. These changes may first affect compartments that are distant from the cell soma, including axons (Karten et al., 2002) and synapses (Karten et al., 2006; Buard and Pfrieger, 2014).

Our study provides new insight into how $\mathrm{HbC}$ reverts the accumulation of cholesterol in neurons with impaired NPC1 activity. Based on preclinical evidence (Liu et al., 2009a; Davidson et al., 2009; Aqul et al., 2011; Vite et al., 2015), this compound is currently being tested in clinical trials as a treatment for NPC disease (Ottinger et al., 2014). Our findings suggest a two-step mechanism of action. First, endocytosed $\mathrm{HbC}$ resolubilizes cholesterol contained in lamellar inclusions and promotes its intracellular redistribution in an NPC1- and
NPC2-independent manner. This process was indicated by several HbC-induced changes in U18-treated and NPC1deficient RGCs. TEM revealed a dose-dependent reduction of lamellae within inclusions. Scanning electron microscopy combined with BSE imaging revealed the presence of inclusions that were partially depleted from cholesterol. Immunocytochemical staining showed a significant decrease in HMGCR, indicating its redistribution to the ER, where it induced a reduction of cholesterol biosynthesis. These changes are in agreement with previously reported effects of $\beta$-cyclodextrin in cultured fibroblasts (Abi-Mosleh et al., 2009; Rosenbaum et al., 2010) and brain cells (Peake and Vance, 2012; Taylor et al., 2012) and in animal models in vivo (Davidson et al., 2009; Liu et al., 2009a; Aqul et al., 2011; Vite et al., 2015). In a second step, HbC enables the exocytotic release of lamellar inclusions from neurons. This surprising mechanism was indicated by several $\mathrm{HbC}$-induced changes detected by our refined scanning electron microscopy techniques. Immunogold labeling revealed an increased density of LAMP1 clusters in the plasma membrane, which indicates exocytosis of LAMP1-positive compartments (Samie and Xu, 2014). A clustered appearance of LAMP1 on the cell surface was also observed after induction of lysosomal exocytosis in natural killer cells (Liu et al., 2009b). Scanning electron microscopy of intact and fractured cells revealed the presence of cholesterol-rich inclusions at the cytoplasmic face of the plasma membrane, on the cell surface, and in culture medium before, during, and after release, respectively. Finally, immunogold labeling of fractured RGCs revealed a close association of cholesterol-rich inclusions with actin and tubulin and with VAMP8, indicating their active transport to the subplasmalemmal space and their SNARE-dependent exocytosis. Notably, all of these changes occurred only in RGCs with impaired NPC1 activity, and not in untreated RGCs or those isolated from wild-type animals. HbC induced these changes at concentrations between 50 of $100 \mu \mathrm{M}$, which have been used previously to revert the NPC phenotype in vitro (Peake and Vance, 2012) and in vivo (Aqul et al., 2011). At 100-fold higher concentrations, $\mathrm{HbC}$ extracts cholesterol from the plasma membrane, induces exocytosis in cultured fibroblasts (Chen et al., 2010), and kills primary neurons (Peake and Vance, 2012).

We hypothesize that the resolubilization of cholesterol from inclusions by $\mathrm{HbC}$ enables their transport to the plasma membrane (Neefjes and van der Kant, 2014) and their release to the extracellular space. The latter provides an efficient means to remove the enormous amounts of accumulated cholesterol that may become toxic, when resolubilized in toto within cells. The ability of neurons to exocytose LAMP1-positive cargo has not been observed previously. Our results suggest that this pathway can serve as target for therapeutic approaches to NPC and other disorders where lysosomal accumulation of macromolecules causes neurodegeneration (Shen et al., 2012; Samie and Xu, 2014).

\section{References}

Abi-Mosleh L, Infante RE, Radhakrishnan A, Goldstein JL, Brown MS (2009) Cyclodextrin overcomes deficient lysosome-to-endoplasmic reticulum transport of cholesterol in Niemann-Pick type C cells. Proc Natl Acad Sci U S A 106:19316-19321. CrossRef Medline

Anders S, Huber W (2010) Differential expression analysis for sequence count data. Genome Biol 11:R106. CrossRef Medline

Anders S, Pyl PT, Huber W (2015) HTSeq-a Python framework to work with high-throughput sequencing data. Bioinformatics 31:166-169. CrossRef Medline 
Angermüller S, Fahimi HD (1982) Imidazole-buffered osmium tetroxide: an excellent stain for visualization of lipids in transmission electron microscopy. Histochem J 14:823-835. CrossRef Medline

Aqul A, Liu B, Ramirez CM, Pieper AA, Estill SJ, Burns DK, Liu B, Repa JJ, Turley SD, Dietschy JM (2011) Unesterified cholesterol accumulation in late endosomes/lysosomes causes neurodegeneration and is prevented by driving cholesterol export from this compartment. J Neurosci 31: 9404-9413. CrossRef Medline

Benjamini Y, Hochberg Y (1995) Controlling the false discovery rate: a practical and powerful approach to multiple testing. J R Stat Soc Ser B Stat Methodol 57:289-300.

Boyles J, Bainton DF (1979) Changing patterns of plasma membraneassociated filaments during the initial phases of polymorphonuclear leukocyte adherence. J Cell Biol 82:347-368. CrossRef Medline

Buard I, Pfrieger FW (2014) Relevance of neuronal and glial NPC1 for synaptic input to cerebellar Purkinje cells. Mol Cell Neurosci 61:65-71. CrossRef Medline

Cenedella RJ (2009) Cholesterol synthesis inhibitor U18666A and the role of sterol metabolism and trafficking in numerous pathophysiological processes. Lipids 44:477-487. CrossRef Medline

Chen FW, Li C, Ioannou YA (2010) Cyclodextrin induces calciumdependent lysosomal exocytosis. PLoS One 5:e15054. CrossRef Medline

Claudepierre T, Paques M, Simonutti M, Buard I, Sahel J, Maue RA, Picaud S, Pfrieger FW (2010) Lack of Niemann Pick type C1 induces age-related degeneration in the mouse retina. Mol Cell Neurosci 43:164-176. CrossRef Medline

Davidson CD, Ali NF, Micsenyi MC, Stephney G, Renault S, Dobrenis K, Ory DS, Vanier MT, Walkley SU (2009) Chronic cyclodextrin treatment of murine Niemann-Pick C disease ameliorates neuronal cholesterol and glycosphingolipid storage and disease progression. PLoS One 4:e6951. CrossRef Medline

Davidson CD, Fishman YI, Puskás I, Szemán J, Sohajda T, McCauliff LA, Sikora J, Storch J, Vanier MT, Szente L, Walkley SU, Dobrenis K (2016) Efficacy and ototoxicity of different cyclodextrins in Niemann-Pick C disease. Ann Clin Transl Neurol 3:366-380. CrossRef Medline

German DC, Quintero EM, Liang CL, Ng B, Punia S, Xie C, Dietschy JM (2001) Selective neurodegeneration, without neurofibrillary tangles, in a mouse model of Niemann-Pick C disease. J Comp Neurol 433:415-425. CrossRef Medline

Gimpl G (2010) Cholesterol-protein interaction: methods and cholesterol reporter molecules. Subcell Biochem 51:1-45. CrossRef Medline

Goldstein JL, DeBose-Boyd RA, Brown MS (2006) Protein sensors for membrane sterols. Cell 124:35-46. CrossRef Medline

Harzer K, Schlote W, Peiffer J, Benz HU, Anzil AP (1978) Neurovisceral lipidosis compatible with Niemann-Pick disease type C: morphological and biochemical studies of a late infantile case and enzyme and lipid assays in a prenatal case of the same family. Acta Neuropathol 43:97-104. CrossRef Medline

Henderson LP, Lin L, Prasad A, Paul CA, Chang TY, Maue RA (2000) Embryonic striatal neurons from niemann-pick type $\mathrm{C}$ mice exhibit defects in cholesterol metabolism and neurotrophin responsiveness. J Biol Chem 275:20179-20187. CrossRef Medline

Huang da W, Sherman BT, Lempicki RA (2009) Systematic and integrative analysis of large gene lists using DAVID bioinformatics resources. Nat Protoc 4:44-57. Medline

Karten B, Vance DE, Campenot RB, Vance JE (2002) Cholesterol accumulates in cell bodies, but is decreased in distal axons, of Niemann-Pick C1-deficient neurons. J Neurochem 83:1154-1163. CrossRef Medline

Karten B, Campenot RB, Vance DE, Vance JE (2006) The Niemann-Pick C1 protein in recycling endosomes of presynaptic nerve terminals. J Lipid Res 47:504-514. Medline

Klumperman J, Raposo G (2014) The complex ultrastructure of the endolysosomal system. Cold Spring Harb Perspect Biol 6:a016857. CrossRef Medline

Kobayashi T, Beuchat MH, Lindsay M, Frias S, Palmiter RD, Sakuraba H, Parton RG, Gruenberg J (1999) Late endosomal membranes rich in lysobisphosphatidic acid regulate cholesterol transport. Nat Cell Biol 1:113-118. CrossRef Medline

Lange Y, Ye J, Steck TL (1998) Circulation of cholesterol between lysosomes and the plasma membrane. J Biol Chem 273:18915-18922. CrossRef Medline
Ledeen RW, Wu G (2015) The multi-tasked life of GM1 ganglioside, a true factotum of nature. Trends Biochem Sci 40:407-418. CrossRef Medline

Liao G, Yao Y, Liu J, Yu Z, Cheung S, Xie A, Liang X, Bi X (2007) Cholesterol accumulation is associated with lysosomal dysfunction and autophagic stress in Npc1-/- mouse brain. Am J Pathol 171:962-975. CrossRef Medline

Lim J, Yue Z (2015) Neuronal aggregates: formation, clearance, and spreading. Dev Cell 32:491-501. CrossRef Medline

Liscum L, Faust JR (1989) The intracellular transport of low density lipoprotein-derived cholesterol is inhibited in Chinese hamster ovary cells cultured with 3-beta-[2-(diethylamino)ethoxy]androst-5-en-17-one. J Biol Chem 264:11796-11806. Medline

Liscum L, Ruggiero RM, Faust JR (1989) The intracellular transport of low density lipoprotein-derived cholesterol is defective in Niemann-Pick type C fibroblasts. J Cell Biol 108:1625-1636. CrossRef Medline

Liu B, Turley SD, Burns DK, Miller AM, Repa JJ, Dietschy JM (2009a) Reversal of defective lysosomal transport in NPC disease ameliorates liver dysfunction and neurodegeneration in the npc1-/- mouse. Proc Natl Acad Sci U S A 106:2377-2382. CrossRef Medline

Liu D, Bryceson YT, Meckel T, Vasiliver-Shamis G, Dustin ML, Long EO (2009b) Integrin-dependent organization and bidirectional vesicular traffic at cytotoxic immune synapses. Immunity 31:99-109. CrossRef Medline

Lloyd-Evans E, Morgan AJ, He X, Smith DA, Elliot-Smith E, Sillence DJ, Churchill GC, Schuchman EH, Galione A, Platt FM (2008) NiemannPick disease type $\mathrm{C} 1$ is a sphingosine storage disease that causes deregulation of lysosomal calcium. Nat Med 14:1247-1255. CrossRef Medline

Loftus SK, Morris JA, Carstea ED, Gu JZ, Cummings C, Brown A, Ellison J, Ohno K, Rosenfeld MA, Tagle DA, Pentchev PG, Pavan WJ (1997) Murine model of Niemann-Pick C disease: mutation in a cholesterol homeostasis gene. Science 277:232-235. CrossRef Medline

Love MI, Huber W, Anders S (2014) Moderated estimation of fold change and dispersion for RNA-seq data with DESeq2. Genome Biol 15:550. CrossRef Medline

Lowenthal AC, Cummings JF, Wenger DA, Thrall MA, Wood PA, de Lahunta A (1990) Feline sphingolipidosis resembling Niemann-Pick disease type C. Acta Neuropathol (Berl) 81:189-197. CrossRef

Lu F, Liang Q, Abi-Mosleh L, Das A, De Brabander JK, Goldstein JL, Brown MS (2015) Identification of NPC1 as the target of U18666A, an inhibitor of lysosomal cholesterol export and Ebola infection. Elife 4:e12177. Medline

Luan Z, Saito Y, Miyata H, Ohama E, Ninomiya H, Ohno K (2008) Brainstem neuropathology in a mouse model of Niemann-Pick disease type C. J Neurol Sci 268:108-116. CrossRef Medline

Marks MS, Heijnen HF, Raposo G (2013) Lysosome-related organelles: unusual compartments become mainstream. Curr Opin Cell Biol 25:495505. CrossRef Medline

Mauch DH, Nägler K, Schumacher S, Göritz C, Müller EC, Otto A, Pfrieger FW (2001) CNS synaptogenesis promoted by glia-derived cholesterol. Science 294:1354-1357. CrossRef Medline

Meyer-Franke A, Kaplan MR, Pfrieger FW, Barres BA (1995) Characterization of the signaling interactions that promote the survival and growth of developing retinal ganglion cells in culture. Neuron 15:805-819. CrossRef Medline

Miller F, Palade GE (1964) Lytic activities in renal protein absoption droplets. An electron microscopical cytochemical study. J Cell Biol 23:519552. CrossRef Medline

Naureckiene S, Sleat DE, Lackland H, Fensom A, Vanier MT, Wattiaux R, Jadot M, Lobel P (2000) Identification of HE1 as the Second Gene of Niemann-Pick C Disease. Science 290:2298-2301. CrossRef Medline

Neefjes J, van der Kant R (2014) Stuck in traffic: an emerging theme in diseases of the nervous system. Trends Neurosci 37:66-76. CrossRef Medline

Nieweg K, Schaller H, Pfrieger FW (2009) Marked differences in cholesterol synthesis between neurons and glial cells from postnatal rats. J Neurochem 109:125-134. CrossRef Medline

Nowotny K, Jung T, Grune T, Höhn A (2014) Accumulation of modified proteins and aggregate formation in aging. Exp Gerontol 57:122-131. CrossRef Medline

Ottinger EA, Kao ML, Carrillo-Carrasco N, Yanjanin N, Shankar RK, Janssen M, Brewster M, Scott I, Xu X, Cradock J, Terse P, Dehdashti SJ, Marugan J, Zheng W, Portilla L, Hubbs A, Pavan WJ, Heiss J, Vite CH, Walkley SU, 
et al. (2014) Collaborative development of 2-hydroxypropyl-betacyclodextrin for the treatment of Niemann-Pick type C1 disease. Curr Top Med Chem 14:330-339. CrossRef Medline

Palmer M, Green WR, Maumenee IH, Valle DL, Singer HS, Morton SJ, Moser HW (1985) Niemann-Pick disease-type C. Ocular histopathologic and electron microscopic studies. Arch Ophthalmol 103:817-822. CrossRef Medline

Parenti G, Andria G, Ballabio A (2015) Lysosomal storage diseases: from pathophysiology to therapy. Annu Rev Med 66:471-486. CrossRef Medline

Peake KB, Vance JE (2012) Normalization of cholesterol homeostasis by 2-hydroxypropyl-beta-cyclodextrin in neurons and glia from NiemannPick C1 (NPC1)-deficient mice. J Biol Chem 287:9290-9298. CrossRef Medline

Phillips SE, Woodruff EA 3rd, III, Liang P, Patten M, Broadie K (2008) Neuronal loss of Drosophila NPCla causes cholesterol aggregation and age-progressive neurodegeneration. J Neurosci 28:6569-6582. CrossRef Medline

Pols MS, Klumperman J (2009) Trafficking and function of the tetraspanin CD63. Exp Cell Res 315:1584-1592. CrossRef Medline

Ramirez CM, Liu B, Aqul A, Taylor AM, Repa JJ, Turley SD, Dietschy JM (2011) Quantitative role of LAL, NPC2, and NPC1 in lysosomal cholesterol processing defined by genetic and pharmacological manipulations. J Lipid Res 52:688-698. CrossRef Medline

Reid PC, Sugii S, Chang TY (2003) Trafficking defects in endogenously synthesized cholesterol in fibroblasts, macrophages, hepatocytes, and glial cells from Niemann-Pick type C1 mice. J Lipid Res 44:1010-1019. CrossRef Medline

Reid PC, Sakashita N, Sugii S, Ohno-Iwashita Y, Shimada Y, Hickey WF, Chang TY (2004) A novel cholesterol stain reveals early neuronal cholesterol accumulation in the Niemann-Pick type C1 mouse brain. J Lipid Res 45:582-591. Medline

Repa JJ, Li H, Frank-Cannon TC, Valasek MA, Turley SD, Tansey MG, Dietschy JM (2007) Liver X receptor activation enhances cholesterol loss from the brain, decreases neuroinflammation, and increases survival of the NPC1 mouse. J Neurosci 27:14470-14480. CrossRef Medline

Rosenbaum AI, Zhang G, Warren JD, Maxfield FR (2010) Endocytosis of beta-cyclodextrins is responsible for cholesterol reduction in NiemannPick type C mutant cells. Proc Natl Acad Sci U S A 107:5477-5482. CrossRef Medline

Runz H, Rietdorf J, Tomic I, de Bernard M, Beyreuther K, Pepperkok R, Hartmann T (2002) Inhibition of intracellular cholesterol transport alters presenilin localization and amyloid precursor protein processing in neuronal cells. J Neurosci 22:1679-1689. Medline

Samie MA, Xu H (2014) Lysosomal exocytosis and lipid storage disorders. J Lipid Res 55:995-1009. CrossRef Medline

Shen D, Wang X, Li X, Zhang X, Yao Z, Dibble S, Dong XP, Yu T, Lieberman AP, Showalter HD, Xu H (2012) Lipid storage disorders block lysosomal trafficking by inhibiting a TRP channel and lysosomal calcium release. Nat Commun 3:731. CrossRef Medline

Sjollema KA, Schnell U, Kuipers J, Kalicharan R, Giepmans BN (2012) Correlated light microscopy and electron microscopy. Methods Cell Biol 111: 157-173. CrossRef Medline
Sokol J, Blanchette-Mackie J, Kruth HS, Dwyer NK, Amende LM, Butler JD, Robinson E, Patel S, Brady RO, Comly ME (1988) Type C NiemannPick disease. Lysosomal accumulation and defective intracellular mobilization of low density lipoprotein cholesterol. J Biol Chem 263:3411-3417. Medline

Steinmetz CC, Buard I, Claudepierre T, Nägler K, Pfrieger FW (2006) Regional variations in the glial influence on synapse development in the mouse CNS. J Physiol 577:249-261. CrossRef Medline

Sugimoto Y, Ninomiya H, Ohsaki Y, Higaki K, Davies JP, Ioannou YA, Ohno K (2001) Accumulation of cholera toxin and GM1 ganglioside in the early endosome of Niemann-Pick C1-deficient cells. Proc Natl Acad Sci U S A 98:12391-12396. CrossRef Medline

Tanaka J, Nakamura H, Miyawaki S (1988) Cerebellar involvement in murine sphingomyelinosis: a new model of Niemann-Pick disease. J Neuropathol Exp Neurol 47:291-300. CrossRef Medline

Taylor AM, Liu B, Mari Y, Liu B, Repa JJ (2012) Cyclodextrin mediates rapid changes in lipid balance in Npcl-/- mice without carrying cholesterol through the bloodstream. J Lipid Res 53:2331-2342. CrossRef Medline

Vance JE, Karten B (2014) Niemann-Pick C disease and mobilization of lysosomal cholesterol by cyclodextrin. J Lipid Res 55:1609-1621. CrossRef Medline

Vanier MT (2015) Complex lipid trafficking in Niemann-Pick disease type C. J Inherit Metab Dis 38:187-199. CrossRef Medline

Vite CH, Bagel JH, Swain GP, Prociuk M, Sikora TU, Stein VM, O'Donnell P, Ruane T, Ward S, Crooks A, Li S, Mauldin E, Stellar S, De Meulder M, Kao ML, Ory DS, Davidson C, Vanier MT, Walkley SU (2015) Intracisternal cyclodextrin prevents cerebellar dysfunction and Purkinje cell death in feline Niemann-Pick type C1 disease. Sci Transl Med 7:276ra26. CrossRef Medline

Wendeler M, Sandhoff K (2009) Hexosaminidase assays. Glycoconj J 26: 945-952. CrossRef Medline

Xie C, Turley SD, Pentchev PG, Dietschy JM (1999) Cholesterol balance and metabolism in mice with loss of function of Niemann-Pick C protein. Am J Physiol 276:E336-E344. Medline

Yamada A, Saji M, Ukita Y, Shinoda Y, Taniguchi M, Higaki K, Ninomiya H, Ohno K (2001) Progressive neuronal loss in the ventral posterior lateral and medial nuclei of thalamus in Niemann-Pick disease type C mouse brain. Brain Dev 23:288-297. CrossRef Medline

Zervas M, Dobrenis K, Walkley SU (2001) Neurons in Niemann-Pick disease type $\mathrm{C}$ accumulate gangliosides as well as unesterified cholesterol and undergo dendritic and axonal alterations. J Neuropathol Exp Neurol 60: 49-64. CrossRef Medline

Zhang J, Leiderman K, Pfeiffer JR, Wilson BS, Oliver JM, Steinberg SL (2006) Characterizing the topography of membrane receptors and signaling molecules from spatial patterns obtained using nanometer-scale electrondense probes and electron microscopy. Micron 37:14-34. CrossRef Medline

Zidovetzki R, Levitan I (2007) Use of cyclodextrins to manipulate plasma membrane cholesterol content: evidence, misconceptions and control strategies. Biochim Biophys Acta 1768:1311-1324. CrossRef Medline 